meqRxiv preprint doi: https://doi.org/10.1101/2020.07.16.20155606; this version posted July 18, 2020. The copyright holder for this preprint

(WHikh Q

It is made available under a CC-BY-NC 4.0 International license .

\title{
1 A high-resolution HLA reference panel capturing global population diversity 2 enables multi-ethnic fine-mapping in HIV host response
}

3 Yang Luo ${ }^{1,2,3,4,5}$, Masahiro Kanai ${ }^{5,4,6,7,8}$, Wanson Choi ${ }^{9}$, Xinyi Li $^{10}$, Kenichi Yamamoto ${ }^{8,11}$, Kotaro

4 Ogawa $^{8,12}$, Maria Gutierrez-Arcelus ${ }^{1,2,3,4,5}$, Peter K. Gregersen ${ }^{13}$, Philip E. Stuart ${ }^{14}$, James T.

5 Elder $^{14,15}$, Jacques Fellay ${ }^{16,17}$, Mary Carrington ${ }^{18,19}$, David W. Haas ${ }^{20,21}$, Xiuqing Guo ${ }^{22}$, Nicholette

6 D. Palmer ${ }^{23}$, Yii-Der Ida Chen ${ }^{22}$, Jerome. I. Rotter ${ }^{22}$, Kent. D. Taylor ${ }^{22}$, Stephen. S. Rich ${ }^{24}$, Adolfo

7 Correa $^{25}$, James G. Wilson ${ }^{26}$, Sekar Kathiresan ${ }^{5,27,28}$, Michael H. Cho ${ }^{29}$, Andres Metspalu ${ }^{30}$, Tonu

8 Esko $^{5,30}$, Yukinori Okada ${ }^{8,31}$, Buhm Han ${ }^{32}$, NHLBI Trans-Omics for Precision Medicine (TOPMed)

9 Consortium, Paul J. McLaren ${ }^{33,34}$, Soumya Raychaudhuri ${ }^{1,2,3,4,5,35}$

101 Center for Data Sciences, Brigham and Women's Hospital, Harvard Medical School, Boston, MA, USA

112 Division of Rheumatology, Immunology, and Immunity, Brigham and Women's Hospital, Harvard

12 Medical School, Boston, MA, USA

133 Division of Genetics, Brigham and Women's Hospital, Harvard Medical School, Boston, MA, USA

144 Department of Biomedical Informatics, Harvard Medical School, Boston, MA, USA

155 Broad Institute of MIT and Harvard, Cambridge, MA, USA

166 Analytic and Translational Genetics Unit, Massachusetts General Hospital, Boston, MA, USA

177 Stanley Center for Psychiatric Research, Broad Institute of Harvard and MIT, Cambridge, MA, USA

188 Department of Statistical Genetics, Osaka University Graduate School of Medicine, Suita, 565-0871,

19 Japan

209 Department of Biomedical Sciences, Seoul National University College of Medicine, Seoul, South Korea

2110 Committee on Genetics, Genomics, and Systems Biology, University of Chicago, Chicago, IL, USA

2211 Department of Pediatrics, Osaka University Graduate School of Medicine, Osaka 565-0871, Japan

2312 Department of Neurology, Osaka University Graduate School of Medicine, Osaka 565-0871, Japan

2413 The Robert S. Boas Center for Genomics and Human Genetics, Feinstein Institute for Medical

25 Research, North Short LIJ Health System, Manhasset, NY, USA

2614 Department of Dermatology, University of Michigan, Ann Arbor, Michigan, USA

2715 Ann Arbor Veterans Affairs Hospital, Ann Arbor, Michigan, USA

2816 Precision Medicine Unit, Lausanne University Hospital and University of Lausanne, Lausanne,

29 Switzerland

3017 School of Life Sciences, EPFL, Lausanne, Switzerland

3118 Basic Science Program, Frederick National Laboratory for Cancer Research, Frederick, Maryland,

32 USA

3319 Ragon Institute of MGH, MIT and Harvard, Boston, Massachusetts, USA

3420 Vanderbilt University Medical Center, Nashville, TN, USA

3521 Meharry Medical College, Nashville, TN, USA

3622 The Institute for Translational Genomics and Population Sciences, Department of Pediatrics, The

37 Lundquist Institute for Biomedical Innovation at Harbor-UCLA Medical Center, Torrance, CA USA

3823 Department of Biochemistry, Wake Forest School of Medicine, Winston-Salem, North Carolina, USA

3924 Center for Public Health Genomics, University of Virginia School of Medicine Charlottesville, VA, USA 
meqRxiv preprint doi: https://doi.org/10.1101/2020.07.16.20155606; this version posted July 18, 2020. The copyright holder for this preprint

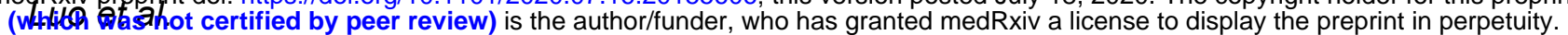
It is made available under a CC-BY-NC 4.0 International license .

4025 Medicine, University of Mississippi Medical Center, MS, USA

4126 Physiology and Biophysics, University of Mississippi Medical Center, MS, USA

4227 Center for Genomic Medicine, Massachusetts General Hospital, Boston, MA, USA

4328 Cardiology Division of the Department of Medicine, Massachusetts General Hospital, Boston, MA,

44 USA

4529 Channing Division of Network Medicine, Department of Medicine, Brigham and Women's Hospital,

46 Harvard Medical School, Boston, MA, USA

4730 Estonian Genome Center, Institute of Genomics, University of Tartu, Estonia

4831 Laboratory of Statistical Immunology, Immunology Frontier Research Center (WPI-IFReC), Osaka

49 University, Suita 565-0871, Japan

5032 Department of Medicine, Seoul National University College of Medicine, Seoul, Korea

5133 J.C. Wilt Infectious Diseases Research Centre, National Microbiology Laboratories, Public Health

52 Agency of Canada, Winnipeg, Canada

5334 Department of Medical Microbiology and Infectious Diseases, University of Manitoba, Winnipeg,

54 Canada

5535 Centre for Genetics and Genomics Versus Arthritis, University of Manchester, Manchester, UK

56 Correspondence to

57 Yang Luo

58 Harvard New Research Building

5977 Avenue Louis Pasteur, Suite 255

60 Boston, MA 02115

61 yangluo@broadinstitute.org

62 Tel: 617-525-4468

63 Soumya Raychaudhuri

64 Harvard New Research Building

6577 Avenue Louis Pasteur, Suite 250

66 Boston, MA 02115

67 soumya@broadinstitute.org

68 Tel: 617-525-4484 Fax: 617-525-4488 
meqRxiv preprint doi: https://doi.org/10.1101/2020.07.16.20155606; this version posted July 18, 2020. The copyright holder for this preprint

\section{Abstract}

Defining causal variation by fine-mapping can be more effective in multi-ethnic genetic studies, particularly in regions such as the MHC with highly population-specific structure. To enable such studies, we constructed a large $(\mathrm{N}=21,546)$ high resolution HLA reference panel spanning five global populations based on whole-genome sequencing data. Expectedly, we observed unique long-range HLA haplotypes within each population group. Despite this, we demonstrated consistently accurate imputation at G-group resolution (94.2\%, 93.7\%, 97.8\% and 93.7\% in Admixed African (AA), East Asian (EAS), European (EUR) and Latino (LAT)). We jointly analyzed genome-wide association studies (GWAS) of HIV-1 viral load from EUR, AA and LAT populations. Our analysis pinpointed the MHC association to three amino acid positions $(97,67$ and 156) marking three consecutive pockets (C, B and D) within the HLA-B peptide binding groove, explaining $12.9 \%$ of trait variance, and obviating effects of previously reported associations from

82 population-specific HIV studies.

83 Main

84 The HLA genes located within the MHC region encode proteins that play essential roles in

85 immune responses including antigen presentation. They account for more heritability than all

86 other variants together for many diseases ${ }^{1-4}$. It also has more reported GWAS trait associations

87 than any other locus ${ }^{5}$. The extended $\mathrm{MHC}$ region spans $6 \mathrm{Mb}$ on chromosome $6 \mathrm{p} 21.3$ and

88 contains more than 260 genes $^{6}$. Due to population-specific positive selection it harbors

89 unusually high sequence variation, longer haplotypes than most of the genome, and haplotypes 
meqRxiv preprint doi: https://doi.org/10.1101/2020.07.16.20155606; this version posted July 18, 2020. The copyright holder for this preprint

(WHikh Q

It is made available under a CC-BY-NC 4.0 International license .

90 that are specific to individual ancestral populations ${ }^{7,8}$. Consequently, the MHC is among the

91 most challenging regions in the genome to analyze. Advances in HLA imputation have enabled

92 population-specific association and fine-mapping studies of this locus ${ }^{2,9-12}$. But despite large

93 effect sizes, fine-mapping in multiple populations simultaneously is challenging without a single

94 large and high-resolution multi-ethnic reference panel. This has caused confusion in some

95 instances. For example, defining the driving HLA alleles may inform the design of antigenic

96 peptides for vaccines ${ }^{13,14}$ for HIV-1, which led to 770,000 deaths in 2018 alone ${ }^{15}$. However,

97 multiple risk HLA risk alleles have been independently reported in different populations ${ }^{1,10,16}$, and

98 it is not clear if they represent truly population-specific signals or are confounded by linkage.

99 Results

\section{Performance evaluation of inferred classical HLA alleles}

101 To build a large-scale multi-ethnic HLA imputation reference panel, we used high-coverage

102 whole genome sequencing (WGS) datasets ${ }^{17-21}$ from the Japan Biological Informatics

103 Consortium $^{20}$, the BioBank Japan Project ${ }^{18}$, the Estonian Biobank ${ }^{22}$, the 1000 Genomes Project

$104(1 \mathrm{KG})^{21}$ and a subset of studies in the TOPMed program (Supplementary Note,

105 Supplementary Table 1-2). To perform HLA typing using WGS data, we extracted reads

106 mapped to the extended MHC region (chr6:25Mb-35Mb) and unmapped reads from 24,338

107 samples. We applied a population reference graph $^{23-25,}$ for the $\mathrm{MHC}$ region to infer classical

108 alleles for three HLA class I genes (HLA-A, $-B$ and $-C$ ) and five class II genes (HLA-DQA1,

$109-D Q B 1,-D R B 1,-D P A 1,-D P B 1)$ at G-group resolution, which determines the sequences of the

110 exons encoding the peptide binding groove. We required samples to have $>20 x$ coverage

111 across all HLA genes (Supplementary Table 1, 3). After quality control our panel included

112 21,546 individuals: 10,187 EUR, 7,849 AA, 2,069 EAS, 952 LAT and 489 SAS. 
meqRxiv preprint doi: https://doi.org/10.1101/2020.07.16.20155606; this version posted July 18, 2020. The copyright holder for this preprint (WHikh Q It is made available under a CC-BY-NC 4.0 International license .

113 To assess the accuracy of the WGS HLA allele calls, we compared the inferred HLA classical

114 alleles to gold standard sequence-based typing (SBT) in 955 1KG subjects and 288 Japanese

115 subjects and quantified concordance. In both cohorts we observed slightly higher average

116 accuracy for class I genes, obtaining 99.0\% (one-field, formally known as two-digit), 99.2\%

117 (amino acid) and 96.5\% (G-group resolution), than class II genes, obtaining 98.7\% (one-field),

118 99.7\% (amino acid) and 96.7\% (G-group resolution, Methods, Supplementary Figure 1,

119 Supplementary Tables 4-5, Extended Data 1).

120 HLA diversity

121 To quantify MHC diversity, we calculated identity-by-descent (IBD) distances ${ }^{26}$ between all

122 individuals using 38,398 MHC single nucleotide polymorphisms (SNPs) included in the

123 multi-ethnic HLA reference panel $(\mathrm{N}=21,546)$ and applied principal component analysis (PCA,

124 Methods). PCA distinguished EUR, EAS and AA as well as the admixed LAT and SAS samples

125 (Figure 1a, Supplementary Figure 2). This reflected widespread $H L A$ allele frequency

126 differences between populations (Figure 1b-c, Supplementary Figure 3). Of 130 unique

127 common (frequency > 1\%) G-group alleles, 129 demonstrated significant differences of

128 frequencies across populations (4 degree-of-freedom Chi-square test, $p$-value $<0.05 / 130$,

129 Supplementary Figure 4). The only exception was $D Q A 1^{*} 01: 01: 01 G$ which was nominally

130 significant (unadjusted $p$-value $=0.047$ ). These differences may be related to adaptive selection.

131 For example, the $B^{*} 53: 01: 01 \mathrm{G}$ allele is enriched in Admixed Africans (11.7\% in AA versus $0.3 \%$

132 in others) and it has been previously associated with malaria protection ${ }^{27,28}$. Consistent with

133 previous reports ${ }^{29,30}$, we observed that HLA-B had the highest allelic diversity $(n=443)$ while 
meqRxiv preprint doi: https://doi.org/10.1101/2020.07.16.20155606; this version posted July 18, 2020. The copyright holder for this preprint (WHikh Q It is made available under a CC-BY-NC 4.0 International license .

134 HLA-DQA1 had the least ( $n=17$, Supplementary Figure 5-6, Supplementary Table 6,

135 Extended Data 1).

136 To understand the haplotype structure of HLA between pairs of HLA genes we calculated a

137 multiallelic linkage disequilibrium (LD) measurement index ${ }^{31-33}, \varepsilon$, which is 0 when there is no

138 LD and 1 when there is perfect LD (Figure 2a). We observed higher $\varepsilon$ between DQA1, DQB1,

139 and $D R B 1$; between $D P A 1$ and $D P B 1$; and between $B$ and $C$ (Supplementary Figure 7). The

140 heterogeneity between different populations was underscored by the presence of

141 population-specific common (frequency $>1 \%$ ) high resolution long-range haplotypes

142 (HLA-A C B DRB1 DQA1 DQB1 DPA1 DPB1, Figure 2b, Supplementary Figure 8-12,

143 Extended Data 2, Methods). The most common within-population haplotype was A24::DP6

144 (HLA-A*24:02:01G C*12:02:01G B*52:01:01G DRB1*15:02:01G DQA1*01:03:01G DQB1*06

$\left.145: 01: 01 G \sim D P A 1^{*} 02: 01: 01 G \sim D P B 1 * 09: 01: 01 G\right)$ found at a frequency of $3.61 \%$ in EAS

146 (Supplementary Figure 8). This haplotype is strongly associated with immune-mediated traits

147 such as $\mathrm{HIV}^{34}$ and ulcerative colitis ${ }^{35}$ in Japanese individuals. The next most common haplotype

148 was the well-described European-specific ancestral haplotype A1::DP1 or $8.1^{36,37}$ (

149 frequency $=2.76 \%$,

150 HLA-A*01:01:01G $C^{*} 07: 01: 01 G \sim B^{*} 08: 01: 01 G \sim D R B 1{ }^{*} 03: 01: 01 G \sim D Q A 1{ }^{*} 05: 01: 01 G \sim D Q B 1{ }^{*} 02$ :

151 01:01G DPA1*02:01:02G DPB1*01:01:01G, Supplementary Figure 9). This haplotype is

152 associated with diverse immunopathological phenotypes in the European population, including

153 systemic lupus erythematosus ${ }^{38}$, myositis ${ }^{39}$ and several other conditions ${ }^{36}$. We observed

154 long-range haplotypes in admixed populations including A1::DP4 in SAS (frequency=1.86\%,

155 Supplementary Figure 10), A30::DP1 in AA (frequency=1.18\%,

156 HLA-A*30:01:01G $C^{*}$ 17:01:01G $B^{*} 42: 01: 01: G \sim D R B 1{ }^{*} 03: 02: 01 G \sim D Q A 1{ }^{*} 04: 01: 01 G \sim D Q B 1 * 04$ 
meqRxiv preprint doi: https://doi.org/10.1101/2020.07.16.20155606; this version posted July 18, 2020. The copyright holder for this preprint

(WHikh Q

It is made available under a CC-BY-NC 4.0 International license .

157

158

159

160

161

162 is associated with psoriasis ${ }^{40}$ and $A * 30: 01 \sim C^{*} 17: 01 \sim B^{*} 42: 01$ is associated with $\mathrm{HIV}^{41}$.

\section{HLA selection signature}

164 Previous studies have suggested that recent natural selection favors African ancestry in the

165 HLA region in admixed populations ${ }^{42-45}$. To test this hypothesis in our data, we obtained WGS

166 data from a subset of individuals within two admixed populations (1,832 AA and 594 LAT,

167 determined by the first three global principal components, Supplementary Figure 13,

168 Supplementary Note). Admixed individuals have genomes that are a mosaic of different

169 ancestries. If genetic variations or haplotypes from an ancestral population are advantageous,

170 then they are under selection and are expected to have higher frequency than by chance. Using

$171 \mathrm{ELAI}^{46}$, we quantified how much the ancestry proportions differed within the $\mathrm{MHC}$ from the

172 genome-wide average. In AA, we observed that the average genome-wide proportion of African

173 ancestry was $74.5 \%$, compared to $78.0 \%$ in the extended $\mathrm{MHC}$ region, corresponding to a 3.42

174 (95\% Cl: 3.35-3.49) standard deviation increase. In LAT, we observed 5.76\% African ancestry

175 genome-wide versus $16.0 \%$ in the extended $\mathrm{MHC}$ region, representing an increase of 4.23

176 (95\% Cl: 4.14-4.31) standard deviations (Methods, Supplementary Figure 14). To ensure our

177 results are robust to different local ancestry inference methods, we applied an alternative

178 method called RFMix ${ }^{47}$ and observed a similarly consistent MHC-specific excess of African

179 ancestry in LAT, and also an excess in AA that was more modest (Supplementary Figure 14). 
meqRxiv preprint doi: https://doi.org/10.1101/2020.07.16.20155606; this version posted July 18, 2020. The copyright holder for this preprint (WHikh Q It is made available under a CC-BY-NC 4.0 International license .

192 To empirically assess imputation accuracy of our reference panel, we first used the publicly available gold-standard HLA types (HLA-A, -B,-C, -DRB1 and -DQB1) of 1,267 diverse samples

194 from AA, EAS, EUR and LAT included in 1KG. We removed 955 overlapping samples within the 195 reference panel, and to ensure a representative analysis we kept 6,007 markers overlapping 196 with the Global Genotyping Array SNPs. Across the five genes, the average G-group resolution 197 accuracies were 94.2\%, 93.7\%, 97.8\% and 93.7\% in AA, EAS, EUR and LAT (Figure 3b-c, 198 Supplementary Table 8, Methods, Extended Data 3). Compared to the T1DGC panel, our 199 multi-ethnic reference panel showed the most improvement for individuals of non-European 200 descent; we obtained 4.27\%, 2.96\%, 2.90\% and 1.05\% improvement at G-group resolution for 201 AA, EAS, LAT, and EUR individuals, respectively (Figure 3d). Increased diversity was 
meqRxiv preprint doi: https://doi.org/10.1101/2020.07.16.20155606; this version posted July 18, 2020. The copyright holder for this preprint

(WHikh Q

It is made available under a CC-BY-NC 4.0 International license .

202 responsible for the improvement; downsampling the reference panel be the same size as the

203 T1DGC panel still yielded superior performance (Figure 3d). To validate our panel further, we

204 imputed HLA alleles into a multi-ethnic cohort of 2,291 individuals from the Genotype and

205 Phenotype (GaP) registry genotyped on the ImmunoChip array. We obtained SBT HLA type

206 information for six classical class I and class II loci (HLA-A, $-B,-C,-D Q A 1,-D Q B 1,-D R B 1)$ in 75

207 samples with diverse ancestral background (25 EUR, 25 EAS and 25 AA, Supplementary

208 Figure 15, Methods). Average accuracies were 99.0\%, 95.7\% and 97.0\% for EUR, EAS and

209 AA respectively when comparing SBT HLA alleles at G-group resolution (Methods, Extended

210 Data 3). Similar to the $1 \mathrm{KG}$ analysis, the multi-ethnic reference panel showed significant

211 improvement for individuals with non-European descent $(6.3 \%$ and $11.1 \%$ improvement for EAS

212 and African individuals respectively at G-group resolution), and a more modest $2 \%$ improvement

213 in EUR (Supplementary Figure 16, Supplementary Table 9).

214 Fine-mapping causal variants of HIV jointly in three populations in the MHC region

215 Next we investigated MHC effects within human immunodeficiency virus type $1(\mathrm{HIV}-1)$ set point

216 viral load. Upon primary infection with HIV-1, the set point viral load is reached after the immune

217 system has developed specific cytotoxic T lymphocytes (CTL) that are able to partially control

218 the virus. It has been well-established that the set point viral load (spVL) varies in the infected

219 population and positively correlates with rate of disease progression ${ }^{49}$. Previous studies

220 suggested that HIV-1 infection has a strong genetic component, and specific HLA class I alleles

221 explain the majority of genetic risk ${ }^{10,50}$. The existence of multiple independent, ancestry-specific,

222 risk-associated alleles has been reported in both European ${ }^{1,10}$ and African American ${ }^{16}$

223 populations. However, without a multi-ethnic reference panel it has not been possible to

224 determine if these signals are consistent across different ancestral groups. 
meqRxiv preprint doi: https://doi.org/10.1101/2020.07.16.20155606; this version posted July 18, 2020. The copyright holder for this preprint (WHikh Q It is made available under a CC-BY-NC 4.0 International license .

225 To define the MHC allelic effects shared across multiple populations, we applied our multi-ethnic 226 MHC reference panel to 7,445 EUR, 3,901 AA and 677 LAT HIV-1 infected subjects (Methods, 227 Supplementary Table 10). Imputation resulted in 640 classical HLA alleles, 4,513 amino acids 228 in HLA proteins and 49,321 SNPs in the extended MHC region for association and fine-mapping

229 230 231

232 We next tested SNPs, amino acid positions and classical HLA alleles across the MHC for association to spVL. We performed this jointly in EUR, AA and LAT population using a linear 234 regression model with sex, principal components and ancestry as covariates (Methods). In 235 agreement with previous studies, we found the strongest spVL-associated classical HLA allele 236 is $B^{*} 57$ (effect size $=-0.84, P_{\text {binary }}=8.68 \times 10^{-144}$ ). This corresponded to a single residue Val97 237 in HLA-B that tracks almost perfectly with $B^{*} 57\left(r^{2}=0.995\right)$ and showed the strongest 238 association of any single residue (effect size $=-0.84, P_{\text {binary }}=5.99 \times 10^{-145}$, Supplementary 239 Figure 18)

240 Then to determine which amino acid positions have independent association with spVL, we 241 tested each of the amino acid positions by grouping haplotypes carrying a specific residue at 242 each position in an additive model $^{2,9}$ (Methods). We found the strongest spVL-associated amino 243 acid variant in HLA-B is as previously reported ${ }^{1,10,16}$ at position 97 (Figure 4a-b, Supplementary 244 Table 11) which strikingly explains $9.06 \%$ of the phenotypic variance. Position 97 in HLA-B was 245 more significant $\left(P_{\text {omnibus }}=2.86 \times 10^{-184}\right.$ ) than any single SNP or classical $H L A$ allele, including 
meqRxiv preprint doi: https://doi.org/10.1101/2020.07.16.20155606; this version posted July 18, 2020. The copyright holder for this preprint (WHikh Q It is made available under a CC-BY-NC 4.0 International license .

$246 B^{*} 57$ (Supplementary Figure 18, Extended Data 4). Of the six allelic variants

247 (Val/Asn/Trp/Thr/Arg/Ser) at this position, the Val residue conferred the strongest protective

248 effect (effect size $=-0.88, P=9.32 \times 10^{-152}$, Supplementary Figure 19) relative to the most

249 common residue Arg (frequency $=47.8 \%$ ). All six amino acid alleles have consistent

250 frequencies and effect sizes across the three population groups (Figure 5a-b, Supplementary

251 Figure 20).

252 We next wanted to test whether there were other independent effects outside of position 97 in

253 HLA-B. After accounting for the effects of amino acid 97 in HLA-B using a conditional haplotype

254 analysis (Methods), we observed a significant independent association at position 67 in HLA-B

$255\left(P_{\text {omnibus }}=2.82 \times 10^{-39}\right.$, Figure 4c-d, Supplementary Table 11). Considering this might be an

256 artifact of forward search, we exhaustively tested all possible pairs of polymorphic amino acid

257 positions in HLA-B. Of 7,260 pairs of amino acid positions, none obtained a better

258 goodness-of-fit than the pair of positions 97 and 67 , which collectively explained $11.2 \%$ variance

259 in spVL (Figure 5e, Supplementary Table 12). At position 67, Met67 residue shows the most

260 protective effect (effect size $=-0.44, P=1.19 \times 10^{-59}$ ) among the five possible amino acids

261 (Cys/Phe/Met/Ser/Tyr) relative to the most common residue Ser (frequency =10.0\%).

262 Conditioning on positions 97 and 67 revealed an additional association at position 156 in HLA-B

$263\left(P_{\text {omnibus }}=1.92 \times 10^{-30}\right.$, Figure 4e-f, Supplementary Table 11). In agreement with the

264 stepwise conditional analysis, when we tested all 287,980 possible combinations of three amino

265 acid positions in HLA-B, the most statistically significant combination of amino acids sites is 67 ,

26697 and $156\left(P=5.68 \times 10^{-244}\right.$, Supplementary Table 13). These three positions explained

267 12.9\% of the variance (Figure 5e). At position 156, residue Arg shows the largest risk effect 
meqRxiv preprint doi: https://doi.org/10.1101/2020.07.16.20155606; this version posted July 18, 2020. The copyright holder for this preprint

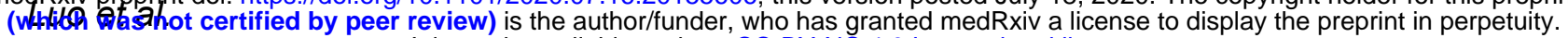
It is made available under a CC-BY-NC 4.0 International license .

268 (effect size $=0.180, P=8.92 \times 10^{-14}$ ) among the four possible allelic variants

269 (Leu/Arg/Asp/Trp), relative to the most common residue Leu (frequency $=35.1 \%$ ).

270 These amino acid positions mark three consecutive pockets within the HLA-B peptide-binding

271 groove (Figure 5c). Position 97 is located in the C-pocket and has an important role in

272 determining the specificity of the peptide-binding groove ${ }^{51,52}$. Position 67 is in the B-pocket, and

273 Met67 side chains occupy the space where larger B-pocket anchors reside in other

274 peptide-MHC structures; its presence limits the size of potential peptide position P2 side

275 chains $^{52}$. Amino acid position 156 is part of the D-pocket and influences the conformation of the

276 peptide-binding region ${ }^{53}$. These results are consistent with the observation that in HLA- $B^{*} 57$, the

277 single most protective spVL-associated one-field allele (a single change at position 156 from

278 Leu $\rightarrow$ Arg or equivalently HLA- $B^{*} 57: 03 \rightarrow$ HLA- $\left.B^{*} 57: 02\right)$ leads to an increased repertoire of

279 HIV-specific epitope ${ }^{41,54}$.

280 Despite differences in the power to detect associations due to differences in allele frequencies

281 (Supplementary Figure 21), we observed generally consistent effects of individual residues

282 across populations (Figure 5d, Supplementary Figure 22-23, Supplementary Table 14).

283 There are 26 unique haplotypes defined by the amino acids at positions 67, 97 and 156 in

284 HLA-B (Table 1, Supplementary Table 15). When we tested for effect size heterogeneity by

285 ancestry for each of these haplotypes (Methods), we observed only 2 of 26 haplotypes showed

286 heterogeneity (F-test $\mathrm{P}$-value $<0.05 / 26)$, possibly due to different interplay between genetic and

287 environmental variation at population-level. These results support the concept that these

288 positions mediate HIV-1 viral load in diverse ancestries. 
meqRxiv preprint doi: https://doi.org/10.1101/2020.07.16.20155606; this version posted July 18, 2020. The copyright holder for this preprint (WHikh Q It is made available under a CC-BY-NC 4.0 International license .

289

290

291

292

294 HLA-A, but larger studies and functional studies will be necessary to define the driving effects.

\section{Discussion}

296

299 multi-ethnic studies is essential for fine-mapping.

300 We showed the utility of this approach by defining the alleles that best explain HIV-1 viral load in 301 infected individuals. Our work implicates three amino acid positions (97, 67 and 156) in HLA-B 302 in conferring the known protective effect of HLA class I variation on HIV-1 infection. Combining 303 all alleles at these three positions explained $12.9 \%$ of the variance in spVL (Figure 5e). These 304 positions all fall within the peptide-binding groove of the respective MHC protein (Figure 5c), 305 indicating that variation in the amino acid content of the peptide-binding groove is the major 306 genetic determinant of HIV control. Supported by experimental studies ${ }^{54-57}$, positions highlighted 307 in our work indicated a structural basis for the HLA association with HIV disease progression 308 that is mediated by the conformation of the peptide within the class I binding groove. This result 309 highlights how a study with ancestrally diverse populations can potentially point to causal 310 variation by leveraging linkage disequilibrium difference between ethnic groups. 
meqRxiv preprint doi: https://doi.org/10.1101/2020.07.16.20155606; this version posted July 18, 2020. The copyright holder for this preprint

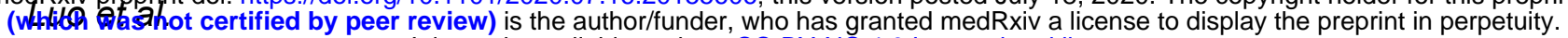
It is made available under a CC-BY-NC 4.0 International license .

311 We note that previous studies have shown position 97 in HLA-B has the strongest association

312 with HIV-1 spVL or case-control in African American and European populations, but highlighted

313 different additional signals via conditional analysis (position 45, 67 in HLA-B and position 77, 95

314 in HLA-A in Europeans ${ }^{1,10,16}$ and position 63, 116 and 245 in HLA-B in African Americans ${ }^{16}$ ).

315 These signals do not explain the signals we report here; after conditioning on positions 45, 63,

316 116, 245 of HLA-B and 95 of HLA-A, the association of the four identified amino acids identified

317 in this study remained significant $\left(P<5 \times 10^{-8}\right)$. In contrast, our binding groove alleles explain

318 these other alleles; conditioning on the four amino acid positions identified in this study

319 (positions 67, 97 and 156 in HLA-B), all previously reported positions did not pass the

320 significance threshold $\left(P>5 \times 10^{-8}\right.$, Supplementary Figure 24).

321 Furthermore, defining the effect sizes for $H L A$ alleles across different populations is essential for

322 defining risk of a wide-range of diseases in the clinical setting. There is increasing application of

323 genome-wide genotyping by patients both by healthcare providers and direct-to-consumer

324 vendors. The large effects of the $\mathrm{MHC}$ region for a wide-range of immune and non-immune

325 traits, makes it essential to define HLA allelic effect sizes essential in multi-ethnic studies in

326 order to build generally applicable clinical polygenic risk scores for many diseases in diverse

327 populations ${ }^{58-61}$. Resources like the one we present here will be an essential ingredient in such

328 studies. 
meqRxiv preprint doi: https://doi.org/10.1101/2020.07.16.20155606; this version posted July 18, 2020. The copyright holder for this preprint

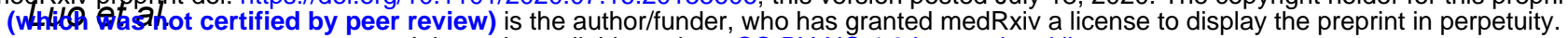
It is made available under a CC-BY-NC 4.0 International license.

\section{Methods}

\section{Individuals included in the reference panel}

331 Study participants were from the Jackson Heart Study (JHS , N =3,027), Multi-Ethnic Study of

332 Atherosclerosis (MESA, N=4,620), Chronic Obstructive Pulmonary Disease Gene (COPDGene)

333 study $(\mathrm{N}=10,623)$, Estonian Biobank (EST, $N=2,244)$, Japan Biological Informatics Consortium

334 (JPN, N=295), Biobank Japan (JPN, N=1,025) and 1000 Genomes Project (1KG, N=2,504).

335 Each study was previously approved by respective institutional review boards (IRBs), including

336 for the generation of WGS data and association with phenotypes. All participants provided

337 written consent. Further details of cohort descriptions and phenotype definitions are described in

338 the Supplementary Note.

\section{HLA-TAPAS}

340 HLA-TAPAS (HLA-Typing At Protein for Association Studies) is an HLA-focused pipeline that

341 can handle HLA reference panel construction (MakeReference), HLA imputation (SNP2HLA),

342 and HLA association (HLAassoc). It is an updated version of the SNP2HLA ${ }^{48}$ to build an

343 imputation reference panel, perform HLA classical allele, amino acid and SNP imputation within

344 the extended MHC region. Briefly, major updates include (1) using PLINK1.9 (URLs) instead of

345 v1.07; (2) using BEAGLE v4.1 (URLs) instead of v3 for phasing and imputation; and (3)

346 including custom $\mathrm{R}$ scripts for performing association and fine-mapping analysis at amino acid

347 level in multiple ancestries. The source code is available for download (URLs). 
meqRxiv preprint doi: https://doi.org/10.1101/2020.07.16.20155606; this version posted July 18, 2020. The copyright holder for this preprint

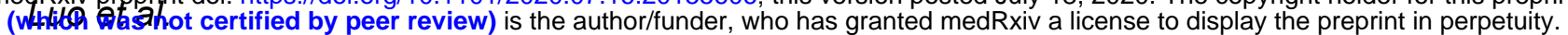

348 Construction of a multi-ethnic HLA reference panel using whole-genome 349 sequences

350 To construct a multi-ethnic HLA imputation reference panel, we used 24,338 whole-genome

351 sequences at different depths (Supplementary Table 1). Details of the construction using

352 deep-coverage whole-genome sequencing are described in the Supplementary Note. Briefly,

353 alignment and variant-calling for genomes sequenced by each cohort were performed

354 independently. We performed local realignment and quality recalibration with the Genome

355 Analysis Toolkit ${ }^{62}$ (GATK; version 3.6) on Chromosome 6:25,000,000-35,000,000. We detected

356 single nucleotide variants (SNV) and indels using GATK with HaplotypeCaller. To eliminate

357 false-positive sites called in the MHC region, we restrict our panel to SNVs reported in 1000

358 Genomes Project ${ }^{21}$ only.

359 We next inferred classical HLA alleles at G-group resolution for eight classical HLA genes

360 (HLA-A, -B, -C, -DQA1, -DQB1, -DRB1, -DPA1 and -DPB1) using a population reference

361 graph $^{24,25}$. To extend the reference panel versatility, we inferred amino acid variation, one-field

362 and two-field resolution alleles from the inferred G-group alleles. After removing samples with

363 low-coverage and failed genome-wide quality control (Supplementary Table 3), we constructed

364 a multi-ethnic HLA imputation reference panel $(\mathrm{N}=21,546)$ using the HLA-TAPAS

365 MakeReference module (URLs, Method). 
meqRxiv preprint doi: https://doi.org/10.1101/2020.07.16.20155606; this version posted July 18, 2020. The copyright holder for this preprint

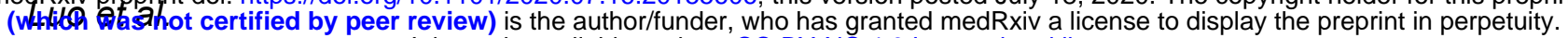

\section{Sequence-based typing of HLA alleles}

367 Purified DNA from the 75 donors from the GaP registry (at the Feinstein Institute for Medical

368 Research) was sent to NHS Blood and Transplant, UK, where HLA typing was performed.

369 Next-generation sequencing was done for HLA-A, $-B,-C,-D Q B 1,-D P B 1$ and $-D R B 1$.

370 PCR-sequence-specific oligonucleotide probe sequencing was performed for HLA-DQA1 in all

371 samples. These typing methods yielded classical allele calls for seven genes at three-field

372 (HLA-A, -B, -C and -DQB1) or G-group resolution (HLA-DQA1, -DPB1 and -DRB1).

373 Genomic DNA from the 288 unrelated samples of Japanese ancestry underwent high-resolution

374 allele typing (three-field alleles) of six classical HLA genes (HLA- $A,-B$ and $-C$ for class I; and

375 HLA-DRB1, -DQA1 and -DPB1 for class II $)^{20}$.

376 The 1000 Genomes panel consists of 1,267 individuals with information on five HLA genes

377 (HLA-A, $-B,-C,-D Q B 1$, and $-D R B 1$ ) at G-group resolution among four major ancestral groups

378 (AA, EAS, EUR and LAT) ${ }^{7}$.

379 We obtained HLA typing of the 1,067 African American subjects included in the HIV-1 viral load

380 study as described previously ${ }^{16,63}$. Briefly, seven classical HLA genes (HLA-A, $-B,-C,-D Q A 1$,

$381-D Q B 1-D R B 1$ and -DPB1) were obtained by sequencing exons 2 and 3 and/or single-stranded

382 conformation polymorphism PCR, and was provided at two-field resolution. 

genotypes

385 Allelic variants at HLA genes can be typed at different resolutions: one-field HLA types specify 386 serological activity, two-field HLA types specify the amino acids encoded by the exons of the 387 HLA gene, and three-field types determine the full exonic sequence including synonymous 388 variants. G-group resolution determines the sequences of the exons encoding the peptide 389 binding groove, that is, exons 2 and 3 for class I and exon 2 class II genes. Thus, any 390 polymorphism occurring in exon 4 of class I gene or exon 3 of class II gene was not defined.

391 This means many G-group alleles can map to multiple three-field and two-field $H L A$ alleles.

392 We calculated the accuracy at each HLA gene by summing across the dosage of each correctly 393 inferred $H L A$ allele or amino acid across all individuals $(N)$, and divided by the total number of 394 observations $\left(2^{*} \mathrm{~N}\right)$. That is,

$$
\operatorname{Accuracy}(g)=\frac{\sum_{i}^{N} D_{i}\left(A_{1 I, g}\right)+D_{i}\left(A_{2 i, g}\right)}{2 N},
$$

396 where Accuracy $(g)$ represents the accuracy at a classical HLA gene (e.g. HLA-B). $D_{i}$

397 represents the inferred dosage of an allele in individual $i$, and alleles $A_{1 i, g}$ and $A_{2 i, g}$ represent 398 the true (SBT) HLA types for an individual $i$.

399 To evaluate the accuracy between the inferred and validated $H L A$ types obtained from SBT at 400 G-group resolution, we translated the highest resolution specified by the validation data to its 401 matching G-group resolution based IMGT/HLA database (e.g. HLA-A*01:01 $\rightarrow$ 402 HLA-A*01:01:01G), and compared it to the primary output from HLA*LA or HLA-TAPAS. We 
meqRxiv preprint doi: https://doi.org/10.1101/2020.07.16.20155606; this version posted July 18, 2020. The copyright holder for this preprint (WHik9 Q It is made available under a CC-BY-NC 4.0 International license . also translated all G-group alleles to their matching amino acid sequences, and compared them against the validation alleles, we referred to this as the amino acid level.

405 To evaluate imputation performance in individual classical $H L A$ alleles and amino acids, we

406 calculated the dosage $r^{2}$ correlation between imputed and SBT dosage.

$407 r^{2}=\left[\sum_{i=1}^{N} x_{i} y_{i}-\left(\sum_{i=1}^{N} x_{i}\right)\left(\sum_{i=1}^{N} y_{i}\right) / N\right]^{2} /\left[\left(\sum_{i=1}^{N} x_{i}^{2}-\left(\sum_{i=1}^{N} x_{i}\right)^{2} / N\right)\left(\sum_{i=1}^{N} y_{i}^{2}-\left(\sum_{i=1}^{N} y_{i}\right)^{2} / N\right)\right]$,

408 where $x_{i}$ and $y_{i}$ represents the inferred and SBT dosage of an allele in individual $i . N$

409 represents the number of individuals.

410 Principal component analysis

411 We performed a principal component analysis of the MHC region based on the

412 identity-by-descent (IBD) distances between all 21,809 individuals included in the multi-ethnic

413 reference panel. We computed the IBD distance using Beagle (Version 4.1, URLs) and

414 averaged over 100 runs with all variants $(54,474)$ included in the HLA reference panel. Due to

415 uneven representation of different ethnicity groups (Supplementary Table 2), we applied a

416 weighted PCA approach, where mean and standard deviation of the IBD matrix within an

417 ethnicity group are weighted inversely proportional to the sample size.

\section{HLA haplotype frequency estimation}

419 We applied an expectation-maximization algorithm approach implemented in Hapl-o-Mat ${ }^{64}$

420 (URLs) to estimate HLA haplotype frequency based on eight classical HLA alleles inferred at

421 G-group resolution. We estimated haplotype frequencies both overall and within five continental

422 populations (Extended Data 2). 
meqRxiv preprint doi: https://doi.org/10.1101/2020.07.16.20155606; this version posted July 18, 2020. The copyright holder for this preprint

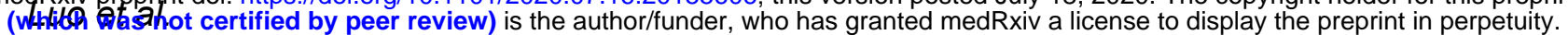
It is made available under a CC-BY-NC 4.0 International license.

\section{Local ancestry inference}

424 To detect local ancestry in admixed samples, we first applied ELAI ${ }^{46}$ to chromosome 6 with 1000

425 Genomes Project ${ }^{21}$ as the reference panel. We extracted 63,998 common HapMap3 SNPs

426 between the WGS (MESA cohort) and the 1000 Genome reference panel. We used the same

427 set of SNPs for ELAl and RFMix analysis. We applied ELAI ${ }^{46}$ to 1,832 African Americans and

428594 Latinos. For 1,832 African American individuals included in the study, we used genotypes of

$42999 \mathrm{CEU}$ and $108 \mathrm{YRI}$ in the 1000 Genome Project as reference panel, assuming admixture

430 generation to be seven generations ago. We used two upper-layer clusters and 10 lower-layer

431 clusters in the model. For Latinos, we selected 65 Latinos with Native American (NAT) ancestry

$432>75 \%$ included in the 1000 Genomes Project identified using the ADMIXTURE analysis ${ }^{65}$ and

433 used these individuals with high NAT, as well as CEU and YRI from 1000 Genomes as

434 reference panels. We assumed that the admixture time was 20 generations ago. For ELAl, we

435 used three upper-layer clusters and 15 lower-layer clusters in the model.

436 To address the technical concerns that local ancestry methods are biased by the high LD of

$437 \mathrm{MHC}$ region ${ }^{66,67}$, we performed an alternative method, $\mathrm{RFMix}{ }^{47}$, for local ancestry inference that

438 accounts for high LD and lack of parental reference panels. Similar deviation from genome-wide

439 ancestry was observed using RFMix (Supplementary Figure 14), indicating that the selection

440 signals we observed here are robust to different inference methods. 
442 We used genome-wide genotyping data from 12,023 HIV-1 infected individuals aggregated

443 across more than 10 different cohorts (Supplementary Table 10). The details of these samples

444 and quality control procedures have been described previously ${ }^{10,68}$. Using the HIV-1 viral load

445 GWAS data, we extracted the genotypes of SNPs located in the extended MHC region

446 (chr6:28-34Mb, Supplementary Table 10). We conducted genotype imputation of one-field,

447 two-field and G-group classical HLA alleles and amino acid polymorphisms of the eight class I

448 and class II HLA genes using the constructed multi-ethnic HLA imputation reference panel and

449 the HLA-TAPAS pipeline.

450 After imputation, we obtained the genotypes of 640 classical alleles, 4,513 amino acid positions 451 of the eight classical HLA genes, and 49,321 SNPs located in the extended MHC region. We

452 excluded variants with MAF $<0.5 \%$ and imputation $r^{2}<0.5$ for all association studies. In total,

453 we tested 51,358 variants in our association and fine-mapping study.

\section{HLA association analysis}

455 For the HIV-1 viral loads of EUR, AA and LAT samples, we conducted a joint haplotype-based

456 association analysis using a linear regression model under the assumption of additive effects of

457 the number of HLA haplotypes for each individual. Phased haplotypes at a locus (i.e., HLA

458 amino acid position) were constructed from the phased imputed genotypes of variants in the

459 locus (i.e., amino acid change or SNP) and were converted to a haplotype matrix where each

460 row is observed haplotypes (in the locus), not genotypes. 
meqRxiv preprint doi: https://doi.org/10.1101/2020.07.16.20155606; this version posted July 18, 2020. The copyright holder for this preprint

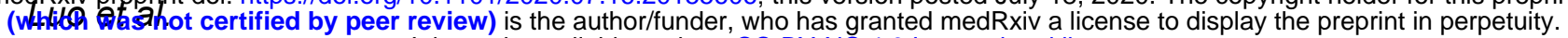
It is made available under a CC-BY-NC 4.0 International license .

461 For each amino acid position, we applied a conditional haplotype analysis. We tested a

462 multiallelic association between the HIV-1 viral load and a haplotype matrix (of the position) with

463 covariates, including sex, study-specific PCs, and a categorical variable indicating a population.

464 That is

$$
y=\beta_{0}+\sum_{i}^{m-1} \beta_{1 i} x_{i}+\sum_{j}^{C} \beta_{2 j} c_{j}
$$

466 where $x_{i}$ is the amino acid haplotype formed by each of the $m$ amino acid residues that occur at 467 that position, and $c_{j}$ are the covariates included in the model.

468 To get an omnibus $P$-value for each position, we estimated the effect of each amino acid by 469 assessing the significance of the improvement in fit by calculating the in-model fit, compared to 470 a null model following an F-distribution with $m-1$ degrees of freedom. This is implemented

471 using an ANOVA test in R as described previously ${ }^{32,69}$. The most frequent haplotype was

472 excluded from a haplotype matrix as a reference haplotype for association.

473 For the conditional analysis, we assumed that the null model consisted of haplotypes as

474 defined by residues at previously defined amino acid positions. The alternative model is in

475 addition of another position with $m$ residues. We tested whether the addition of those amino

476 acid positions, and the creation of $k$ additional haplotypes groups, improved on the previous

477 set. We then assessed the significance of the improvement in the delta deviance (sum of

478 squares) over the previous model using an F-test. We performed stepwise conditional analysis

479 to identify additional independent signals by adjusting for the most significant amino acid

480 position in each step until none met the significance threshold $\left(P=5 \times 10^{-8}\right)$. We restricted 
meqRxiv preprint doi: https://doi.org/10.1101/2020.07.16.20155606; this version posted July 18, 2020. The copyright holder for this preprint

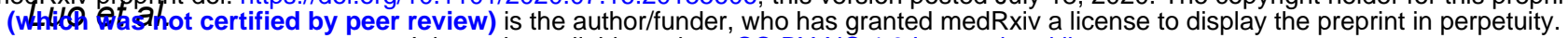
It is made available under a CC-BY-NC 4.0 International license.

483

484 For each set of amino acid positions, we used the groups of residues occurring at these

485 positions to estimate effect size and calculated for each of these models the delta deviance in

486 risk prediction and its p-values compared to the null model.

analysis to haplotypes that have a minimum of 10 occurrences within HLA-B, and removed any individual with rare haplotypes for the conditional analysis.

\section{Heterogeneity testing of effect sizes}

488 We used interaction analyses with models that included haplotype-by-ancestry (Haplotype $x$

489 Ancestry) interaction terms. The fit of nested models was compared to a null model using the

490 F-statistic with two degrees of freedom, for which the association interaction P-value indicated

491 whether the inclusion of the Haplotype $x$ Ancestry interaction terms improved the model fit

492 compared to the null model that did not include the interaction terms. Interaction P-values for all

493 haplotypes formed by positions 97, 67 and 156 in HLA-B are listed in Supplementary Table 15.

494 Haplotypes that had a significant Bonferroni-corrected Haplotype x Ancestry interaction

495 heterogeneity $\mathrm{P}$-value $(\mathrm{P}<0.05 / 26)$ were considered to show evidence of significant effect size

496 heterogeneity between ancestries.

\section{URLs}

498 HLA-TAPAS, https://github.com/immunogenomics/HLA-TAPAS

499 IMGT/HLA, https://www.ebi.ac.uk/ipd/imgt/hla/;

500 GATK version 3.6, https://software.broadinstitute.org/gatk/download/archive;

501 HLA*LA, https://github.com/DiltheyLab/HLA-PRG-LA; 
meqRxiv preprint doi: https://doi.org/10.1101/2020.07.16.20155606; this version posted July 18, 2020. The copyright holder for this preprint (whith 9 解hot certified by peer review) is the author/funder, who has granted medRxiv a license to display the preprint in perpetuity.

It is made available under a CC-BY-NC 4.0 International license .

502 PLINK 1.90, https://www.cog-genomics.org/plink2;

503 Beagle 4.1, https://faculty.washington.edu/browning/beagle/b4_1.html;

504 Hapl-o-Mat, https://github.com/DKMS/Hapl-o-Mat/;

5051000 Genomes gold-standard HLA types,

506 http://ftp.1000genomes.ebi.ac.uk/vol1/ftp/data_collections/HLA_types/

\section{Acknowledgements}

508 The study was supported by the National Institutes of Health (NIH) TB Research Unit Network, 509 Grant U19 Al111224-01.

510 The views expressed in this manuscript are those of the authors and do not necessarily

511 represent the views of the National Heart, Lung, and Blood Institute; the National Institutes of

512 Health; or the U.S. Department of Health and Human Services.

513 The Genotype and Phenotype (GaP) Registry at The Feinstein Institute for Medical Research

514 provided fresh, de-identified human plasma; blood was collected from control subjects under an

515 IRB-approved protocol (IRB\# 09-081) and processed to isolate plasma. The GaP is a

516 sub-protocol of the Tissue Donation Program (TDP) at Northwell Health and a national resource

517 for genotype-phenotype studies.

518 https://www.feinsteininstitute.org/robert-s-boas-center-for-genomics-and-human-genetics/gap-re

519 gistryl

520 A.M. is supported by Gentransmed grant 2014-2020.4.01.15-0012. ; D.W.H. is supported by

521 NIH grants Al110527, Al077505, TR000445, AI069439, and Al110527. D.H.S. was supported by 
meqRxiv preprint doi: https://doi.org/10.1101/2020.07.16.20155606; this version posted July 18, 2020. The copyright holder for this preprint

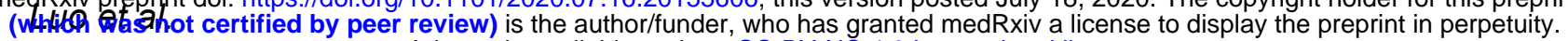
It is made available under a CC-BY-NC 4.0 International license .

R01 HL92301, R01 HL67348, R01 NS058700, R01 AR48797, R01 DK071891, R01 AG058921,

523 the General Clinical Research Center of the Wake Forest University School of Medicine (M01

524 RR07122, F32 HL085989), the American Diabetes Association, and a pilot grant from the

525 Claude Pepper Older Americans Independence Center of Wake Forest University Health

526 Sciences (P60 AG10484). J.T.E. and P.E.S. were supported by NIH/NIAMS R01 AR042742,

527 R01 AR050511, and R01 AR063611.

528 For some HIV cohort participants, DNA and data collection was supported by NIH/NIAID AIDS

529 Clinical Trial Group (ACTG) grants UM1 AI068634, UM1 AI068636 and UM1 Al106701, and

530 ACTG clinical research site grants A1069412, A1069423, A1069424, A1069503, AI025859,

531 Al025868, Al027658, Al027661, Al027666, AI027675, Al032782, AI034853, AI038858,

532 Al045008, Al046370, Al046376, Al050409, Al050410, Al050410, Al058740, Al060354,

533 Al068636, Al069412, Al069415, Al069418, Al069419, Al069423, Al069424, AI069428,

534 Al069432, Al069432, Al069434, Al069439, Al069447, Al069450, Al069452, Al069465,

535 Al069467, Al069470, Al069471, Al069472, Al069474, Al069477, Al069481, Al069484,

536 Al069494, Al069495, Al069496, Al069501, Al069501, Al069502, Al069503, Al069511,

537 Al069513, Al069532, Al069534, Al069556, Al072626, Al073961, RR000046, RR000425,

538 RR023561, RR024156, RR024160, RR024996, RR025008, RR025747, RR025777, RR025780,

539 TR000004, TR000058, TR000124, TR000170, TR000439, TR000445, TR000457, TR001079,

540 TR001082, TR001111, and TR024160.

541 Molecular data for the Trans-Omics in Precision Medicine (TOPMed) program was supported by 542 the National Heart, Lung and Blood Institute (NHLBI). See the TOPMed Omics Support Table

543 (Supplementary Table 16) for study specific omics support information. Core support including 
meqRxiv preprint doi: https://doi.org/10.1101/2020.07.16.20155606; this version posted July 18, 2020. The copyright holder for this preprint (WHikh Q It is made available under a CC-BY-NC 4.0 International license .

544 centralized genomic read mapping and genotype calling, along with variant quality metrics and

545 filtering were provided by the TOPMed Informatics Research Center (3R01HL-117626-02S1;

546 contract HHSN268201800002I). Core support including phenotype harmonization, data

547 management, sample-identity QC, and general program coordination were provided by the

548 TOPMed Data Coordinating Center (R01HL-120393; U01HL-120393; contract

549 HHSN268201800001I). We gratefully acknowledge the studies and participants who provided

550 biological samples and data for TOPMed.

551 The COPDGene project was supported by Award Number U01 HL089897 and Award Number

552 U01 HL089856 from the National Heart, Lung, and Blood Institute. The content is solely the

553 responsibility of the authors and does not necessarily represent the official views of the National

554 Heart, Lung, and Blood Institute or the National Institutes of Health. The COPDGene project is

555 also supported by the COPD Foundation through contributions made to an Industry Advisory

556 Board comprised of AstraZeneca, Boehringer Ingelheim, GlaxoSmithKline, Novartis, Pfizer,

557 Siemens and Sunovion. A full listing of COPDGene investigators can be found at:

558 http://www.copdgene.org/directory

559 The Jackson Heart Study (JHS) is supported and conducted in collaboration with Jackson

560 State University (HHSN268201800013I), Tougaloo College (HHSN268201800014I), the

561 Mississippi State Department of Health (HHSN268201800015I) and the University of Mississippi

562 Medical Center (HHSN268201800010I, HHSN268201800011I and HHSN268201800012I)

563 contracts from the National Heart, Lung, and Blood Institute (NHLBI) and the National Institute

564 on Minority Health and Health Disparities (NIMHD). The authors also wish to thank the staffs

565 and participants of the JHS. 
meqRxiv preprint doi: https://doi.org/10.1101/2020.07.16.20155606; this version posted July 18, 2020. The copyright holder for this preprint (WHikh Q It is made available under a CC-BY-NC 4.0 International license .

566 MESA and the MESA SHARe project are conducted and supported by the National Heart, Lung, 567 and Blood Institute (NHLBI) in collaboration with MESA investigators. Support for MESA is 568 provided by contracts 75N92020D00001, HHSN268201500003I, N01-HC-95159,

569 75N92020D00005, N01-HC-95160, 75N92020D00002, N01-HC-95161, 75N92020D00003,

570 N01-HC-95162, 75N92020D00006, N01-HC-95163, 75N92020D00004, N01-HC-95164,

571 75N92020D00007, N01-HC-95165, N01-HC-95166, N01-HC-95167, N01-HC-95168,

572 N01-HC-95169, UL1-TR-000040, UL1-TR-001079, UL1-TR-001420. MESA Family is conducted

573 and supported by the National Heart, Lung, and Blood Institute (NHLBI) in collaboration with

574 MESA investigators. Support is provided by grants and contracts R01HL071051,

575 R01HL071205, R01HL071250, R01HL071251, R01HL071258, R01HL071259, by the National

576 Center for Research Resources, Grant UL1RR033176. The provision of genotyping data was

577 supported in part by the National Center for Advancing Translational Sciences, CTSI grant

578 UL1TR001881, and the National Institute of Diabetes and Digestive and Kidney Disease

579 Diabetes Research Center (DRC) grant DK063491 to the Southern California Diabetes

580 Endocrinology Research Center. This project has been funded in whole or in part with federal

581 funds from the Frederick National Laboratory for Cancer Research, under Contract No.

582 HHSN261200800001E. The content of this publication does not necessarily reflect the views or

583 policies of the Department of Health and Human Services, nor does mention of trade names,

584 commercial products, or organizations imply endorsement by the U.S. Government. This

585 Research was supported in part by the Intramural Research Program of the NIH, Frederick

586 National Lab, Center for Cancer Research. 
meqRxiv preprint doi: https://doi.org/10.1101/2020.07.16.20155606; this version posted July 18, 2020. The copyright holder for this preprint

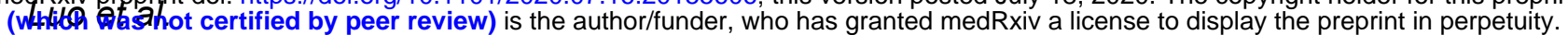
It is made available under a CC-BY-NC 4.0 International license .

\section{Author contributions}

588 Y. L. and S.R. conceived, designed and performed analyses, wrote the manuscript and

589 supervised the research. M.K. implemented the omnibus test for the HIV-1 fine-mapping study.

590 Y.L., W.C., M.K., P.E.S., J.T.E., and B.H. contributed to the development of the HLA-TAPAS

591 pipeline. X.L. performed the selection analysis. J.T.E, M.G.-A. and P.K.G helped with the GaP

592 data acquisition. K.Y., K.O., D.W.H., X.G., N.D.P., Y.I.C., J.I.R., K.D.T., S.S.R., A.C., J.G.W.,

593 S.K., M.H.C., A.M., T.E., and Y.O. contributed to the WGS data acquisition. J.F., M.C. and P.J.M

594 contributed to the HIV-1 data acquisition. All authors contributed to the writing of the manuscript.

\section{Competing interests}

596 M.H.C. has received consulting or speaking fees from Illumina and AstraZeneca, and grant 597 support from GSK and Bayer.

\section{References}

599 1. International HIV Controllers Study et al. The major genetic determinants of HIV-1 control 600 affect HLA class I peptide presentation. Science 330, 1551-1557 (2010).

601 2. Raychaudhuri, S. et al. Five amino acids in three HLA proteins explain most of the 602 association between MHC and seropositive rheumatoid arthritis. Nat. Genet. 44, 291-296 $603 \quad$ (2012).

604 3. Evans, D. M. et al. Interaction between ERAP1 and HLA-B27 in ankylosing spondylitis 605 implicates peptide handling in the mechanism for HLA-B27 in disease susceptibility. Nat.

$606 \quad$ Genet. 43, 761-767 (2011).

607 4. Snyder, A. et al. Genetic basis for clinical response to CTLA-4 blockade in melanoma. $N$. 608 Engl. J. Med. 371, 2189-2199 (2014). 
meqRxiv preprint doi: https://doi.org/10.1101/2020.07.16.20155606; this version posted July 18, 2020. The copyright holder for this preprint

(WHik9 Q

It is made available under a CC-BY-NC 4.0 International license .

609 5. Buniello, A. et al. The NHGRI-EBI GWAS Catalog of published genome-wide association

610 studies, targeted arrays and summary statistics 2019. Nucleic Acids Research vol. 47

611 D1005-D1012 (2019).

612 6. Horton, R. et al. Gene map of the extended human MHC. Nat. Rev. Genet. 5, 889-899

613 (2004).

614 7. Gourraud, P.-A. et al. HLA diversity in the 1000 genomes dataset. PLoS One 9, e97282

615 (2014).

616 8. Robinson, J. et al. IPD-IMGT/HLA Database. Nucleic Acids Res. 48, D948-D955 (2020).

617 9. Hu, X. et al. Additive and interaction effects at three amino acid positions in HLA-DQ and

618 HLA-DR molecules drive type 1 diabetes risk. Nat. Genet. 47, 898-905 (2015).

619 10. McLaren, P. J. et al. Polymorphisms of large effect explain the majority of the host genetic

620 contribution to variation of HIV-1 virus load. Proc. Natl. Acad. Sci. U. S. A. 112,

621 14658-14663 (2015).

622 11. Tian, C. et al. Genome-wide association and HLA region fine-mapping studies identify 623 susceptibility loci for multiple common infections. Nat. Commun. 8, 599 (2017).

624 12. Onengut-Gumuscu, S. et al. Type 1 Diabetes Risk in African-Ancestry Participants and 625 Utility of an Ancestry-Specific Genetic Risk Score. Diabetes Care 42, 406-415 (2019).

626 13. Matthews, P. C. et al. Central role of reverting mutations in HLA associations with human 627 immunodeficiency virus set point. J. Virol. 82, 8548-8559 (2008).

628 14. Wang, Y. Development of a human leukocyte antigen-based HIV vaccine. F1000Res. 7, 629 (2018).

630 15. WHO | Progress reports on HIV. (2020).

631 16. McLaren, P. J. et al. Fine-mapping classical HLA variation associated with durable host 632 control of HIV-1 infection in African Americans. Hum. Mol. Genet. 21, 4334-4347 (2012). 
meqRxiv preprint doi: https://doi.org/10.1101/2020.07.16.20155606; this version posted July 18, 2020. The copyright holder for this preprint

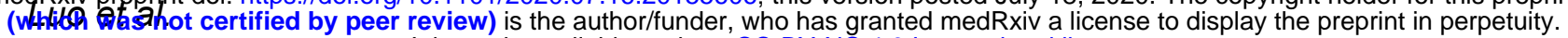
It is made available under a CC-BY-NC 4.0 International license .

633 17. Taliun, D. et al. Sequencing of 53,831 diverse genomes from the NHLBI TOPMed Program. 634 bioRxiv 563866 (2019) doi:10.1101/563866.

635 18. Okada, Y. et al. Deep whole-genome sequencing reveals recent selection signatures linked 636 to evolution and disease risk of Japanese. Nat. Commun. 9, 1631 (2018).

637 19. Mitt, M. et al. Improved imputation accuracy of rare and low-frequency variants using 638 population-specific high-coverage WGS-based imputation reference panel. Eur. J. Hum.

639 Genet. 25, 869-876 (2017).

640

641

642

20. Hirata, J. et al. Genetic and phenotypic landscape of the major histocompatibilty complex region in the Japanese population. Nat. Genet. (2019) doi:10.1038/s41588-018-0336-0.

21. 1000 Genomes Project Consortium et al. A global reference for human genetic variation. Nature 526, 68-74 (2015).

22. Nelis, M. et al. Genetic structure of Europeans: a view from the north--east. PLoS One 4, (2009).

23. Dilthey, A., Cox, C., Iqbal, Z., Nelson, M. R. \& McVean, G. Improved genome inference in the MHC using a population reference graph. Nature Genetics vol. 47 682-688 (2015).

24. Dilthey, A. T. et al. High-Accuracy HLA Type Inference from Whole-Genome Sequencing Data Using Population Reference Graphs. PLoS Comput. Biol. 12, e1005151 (2016).

25. Dilthey, A. T. et al. HLA*LA-HLA typing from linearly projected graph alignments.

Bioinformatics 35, 4394-4396 (2019).

26. Browning, B. L. \& Browning, S. R. A fast, powerful method for detecting identity by descent. Am. J. Hum. Genet. 88, 173-182 (2011).

27. Hill, A. V. et al. Common west African HLA antigens are associated with protection from severe malaria. Nature 352, 595-600 (1991).

28. Sanchez-Mazas, A. et al. The HLA-B landscape of Africa: Signatures of pathogen-driven 
selection and molecular identification of candidate alleles to malaria protection. Mol. Ecol. 26, 6238-6252 (2017).

29. Maiers, M., Gragert, L. \& Klitz, W. High-resolution HLA alleles and haplotypes in the United States population. Hum. Immunol. 68, 779-788 (2007).

30. Gonzalez-Galarza, F. F. et al. Allele frequency net database (AFND) 2020 update: gold-standard data classification, open access genotype data and new query tools. Nucleic Acids Res. 48, D783-D788 (2020).

31. Nothnagel, M., Fürst, R. \& Rohde, K. Entropy as a measure for linkage disequilibrium over multilocus haplotype blocks. Hum. Hered. 54, 186-198 (2002).

32. Okada, Y. et al. Construction of a population-specific HLA imputation reference panel and its application to Graves' disease risk in Japanese. Nat. Genet. 47, 798-802 (2015).

33. Okada, Y. eLD: entropy-based linkage disequilibrium index between multiallelic sites. Hum Genome Var 5, 29 (2018).

34. Chikata, T. et al. Host-specific adaptation of HIV-1 subtype B in the Japanese population. J. Virol. 88, 4764-4775 (2014).

35. Nomura, E. et al. Mapping of a disease susceptibility locus in chromosome $6 p$ in Japanese patients with ulcerative colitis. Genes Immun. 5, 477-483 (2004).

36. Price, P. et al. The genetic basis for the association of the 8.1 ancestral haplotype (A1, B8, DR3) with multiple immunopathological diseases. Immunol. Rev. 167, 257-274 (1999).

37. Horton, R. et al. Variation analysis and gene annotation of eight MHC haplotypes: the MHC Haplotype Project. Immunogenetics 60, 1-18 (2008).

38. Graham, R. R. et al. Visualizing human leukocyte antigen class II risk haplotypes in human systemic lupus erythematosus. Am. J. Hum. Genet. 71, 543-553 (2002).

680 39. Miller, F. W. et al. Genome-wide association study identifies HLA 8.1 ancestral haplotype 
meqRxiv preprint doi: https://doi.org/10.1101/2020.07.16.20155606; this version posted July 18, 2020. The copyright holder for this preprint

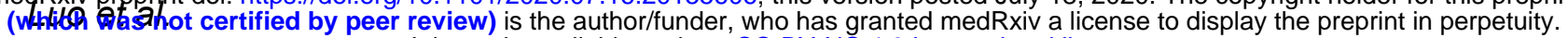
It is made available under a CC-BY-NC 4.0 International license . alleles as major genetic risk factors for myositis phenotypes. Genes Immun. 16, 470-480 (2015).

40. Haapasalo, K. et al. The Psoriasis Risk Allele HLA-C*06:02 Shows Evidence of Association with Chronic or Recurrent Streptococcal Tonsillitis. Infect. Immun. 86, (2018).

41. Kløverpris, H. N. et al. HIV control through a single nucleotide on the HLA-B locus. J. Virol. 86, 11493-11500 (2012).

42. Salter-Townshend, M. \& Myers, S. Fine-Scale Inference of Ancestry Segments Without Prior Knowledge of Admixing Groups. Genetics 212, 869-889 (2019).

43. Zhou, Q., Zhao, L. \& Guan, Y. Strong Selection at MHC in Mexicans since Admixture. PLoS Genet. 12, e1005847 (2016).

44. Meyer, D., C Aguiar, V. R., Bitarello, B. D., C Brandt, D. Y. \& Nunes, K. A genomic perspective on HLA evolution. Immunogenetics 70, 5-27 (2018).

45. Norris, E. T. et al. Admixture-enabled selection for rapid adaptive evolution in the Americas. bioRxiv 783845 (2019) doi:10.1101/783845.

46. Guan, Y. Detecting structure of haplotypes and local ancestry. Genetics 196, 625-642 (2014).

47. Maples, B. K., Gravel, S., Kenny, E. E. \& Bustamante, C. D. RFMix: a discriminative modeling approach for rapid and robust local-ancestry inference. Am. J. Hum. Genet. 93, 278-288 (2013).

48. Jia, X. et al. Imputing amino acid polymorphisms in human leukocyte antigens. PLoS One 8, e64683 (2013).

49. Mellors, J. W. et al. Quantitation of HIV-1 RNA in plasma predicts outcome after seroconversion. Ann. Intern. Med. 122, 573-579 (1995).

4 50. Bartha, I. et al. Estimating the Respective Contributions of Human and Viral Genetic 
Variation to HIV Control. PLoS Comput. Biol. 13, e1005339 (2017).

706

707

708

51. Blanco-Gelaz, M. A. et al. The amino acid at position 97 is involved in folding and surface expression of HLA-B27. Int. Immunol. 18, 211-220 (2006).

52. Stewart-Jones, G. B. E. et al. Structures of Three HIV-1 HLA-B ${ }^{\star 5703-P e p t i d e ~ C o m p l e x e s ~}$ and Identification of Related HLAs Potentially Associated with Long-Term Nonprogression. The Journal of Immunology vol. 175 2459-2468 (2005).

53. Archbold, J. K. et al. Natural micropolymorphism in human leukocyte antigens provides a basis for genetic control of antigen recognition. J. Exp. Med. 206, 209-219 (2009).

54. Gaiha, G. D. et al. Structural topology defines protective CD8+ T cell epitopes in the HIV proteome. Science 364, 480-484 (2019).

55. Macdonald, W. A. et al. A naturally selected dimorphism within the HLA-B44 supertype alters class I structure, peptide repertoire, and T cell recognition. J. Exp. Med. 198, 679-691 (2003).

56. Kloverpris, H. N. et al. HLA-B*57 Micropolymorphism Shapes HLA Allele-Specific Epitope Immunogenicity, Selection Pressure, and HIV Immune Control. Journal of Virology vol. 86 919-929 (2012).

57. Carrington, M. \& Walker, B. D. Immunogenetics of spontaneous control of HIV. Annu. Rev. Med. 63, 131-145 (2012).

58. Khera, A. V. et al. Genome-wide polygenic scores for common diseases identify individuals with risk equivalent to monogenic mutations. Nat. Genet. 50, 1219-1224 (2018).

59. Khera, A. V. et al. Polygenic Prediction of Weight and Obesity Trajectories from Birth to Adulthood. Cell 177, 587-596.e9 (2019).

60. Torkamani, A. \& Topol, E. Polygenic Risk Scores Expand to Obesity. Cell vol. 177 518-520 (2019). 
meqRxiv preprint doi: https://doi.org/10.1101/2020.07.16.20155606; this version posted July 18, 2020. The copyright holder for this preprint

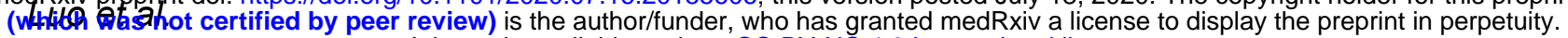
It is made available under a CC-BY-NC 4.0 International license .

61. Martin, A. R. et al. Clinical use of current polygenic risk scores may exacerbate health disparities. Nat. Genet. 51, 584-591 (2019).

62. Van der Auwera, G. A. et al. From FastQ data to high confidence variant calls: the Genome Analysis Toolkit best practices pipeline. Curr. Protoc. Bioinformatics 43, 11.10.1-33 (2013).

63. Julg, B. et al. Possession of HLA class II DRB1*1303 associates with reduced viral loads in chronic HIV-1 clade C and B infection. J. Infect. Dis. 203, 803-809 (2011).

64. Schäfer, C., Schmidt, A. H. \& Sauter, J. Hapl-o-Mat: open-source software for HLA haplotype frequency estimation from ambiguous and heterogeneous data. BMC Bioinformatics 18, 284 (2017).

65. Alexander, D. H., Novembre, J. \& Lange, K. Fast model-based estimation of ancestry in unrelated individuals. Genome Res. 19, 1655-1664 (2009).

66. Price, A. L. et al. Long-range LD can confound genome scans in admixed populations. American journal of human genetics vol. 83 132-5; author reply 135-9 (2008).

67. Pasaniuc, B. et al. Analysis of Latino populations from GALA and MEC studies reveals genomic loci with biased local ancestry estimation. Bioinformatics 29, 1407-1415 (2013).

68. McLaren, P. J. et al. Association study of common genetic variants and HIV-1 acquisition in 6,300 infected cases and 7,200 controls. PLoS Pathog. 9, e1003515 (2013).

69. Okada, Y. et al. Contribution of a Non-classical HLA Gene, HLA-DOA, to the Risk of Rheumatoid Arthritis. Am. J. Hum. Genet. 99, 366-374 (2016). 
meqRxiv preprint doi: https://doi.org/10.1101/2020.07.16.20155606; this version posted July 18, 2020. The copyright holder for this preprint (WHith QtG It is made available under a CC-BY-NC 4.0 International license .

\section{${ }_{748}$ Figures}

749 Figure 1. Global diversity of the MHC region. (a) Principal component analysis of the

750 pairwise IBD distance between 21,546 samples using MHC region markers. Allele diversity of

751 (b) HLA-B and (c) HLA-DQA1 among five continental populations (AA=Admixed African;

752 EUR=European; LAT=Latino; EAS=East Asian; SAS=South Asian). The top two most common

753 alleles within each population group are named, the remaining alleles are grouped as 'others'.

$754(\mathbf{a})$

Population • Admixed African • East Asian • European • Latino • South Asian

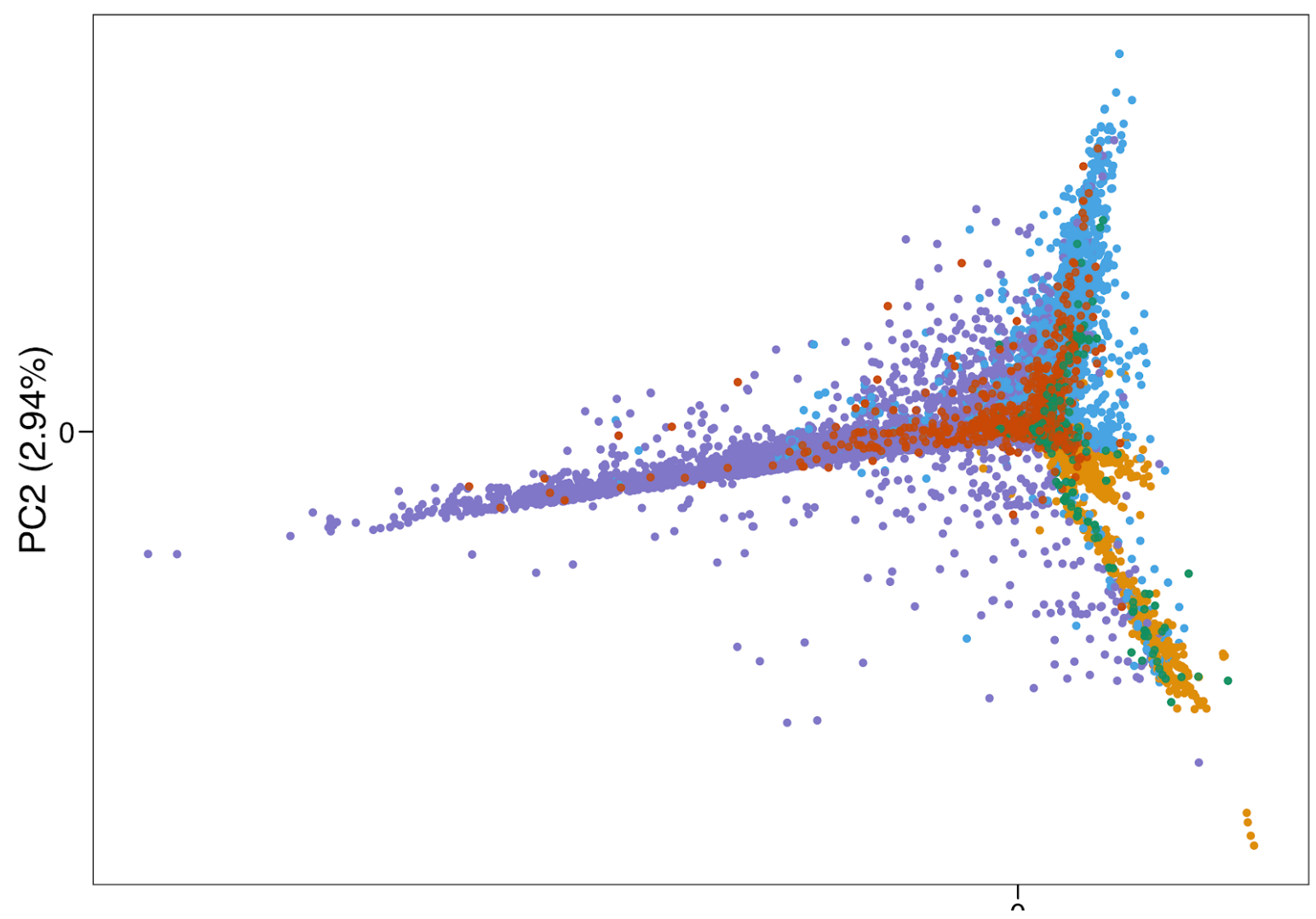


meqRxiv preprint doi: https://doi.org/10.1101/2020.07.16.20155606; this version posted July 18, 2020. The copyright holder for this preprint (whith 9 thashot certified by peer review) is the author/funder, who has granted medRxiv a license to display the preprint in perpetuity.

It is made available under a CC-BY-NC 4.0 International license .

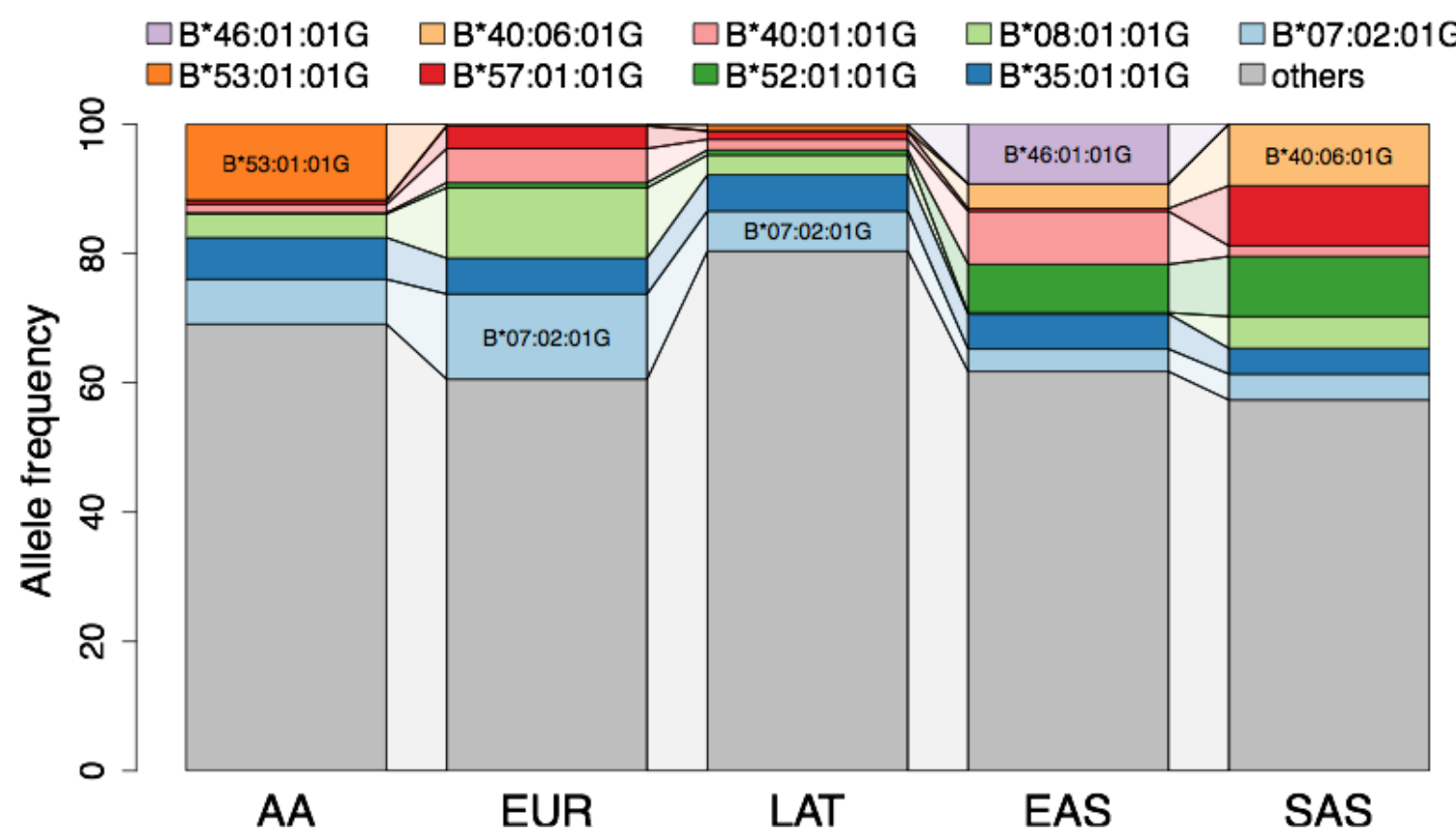

756 (c)

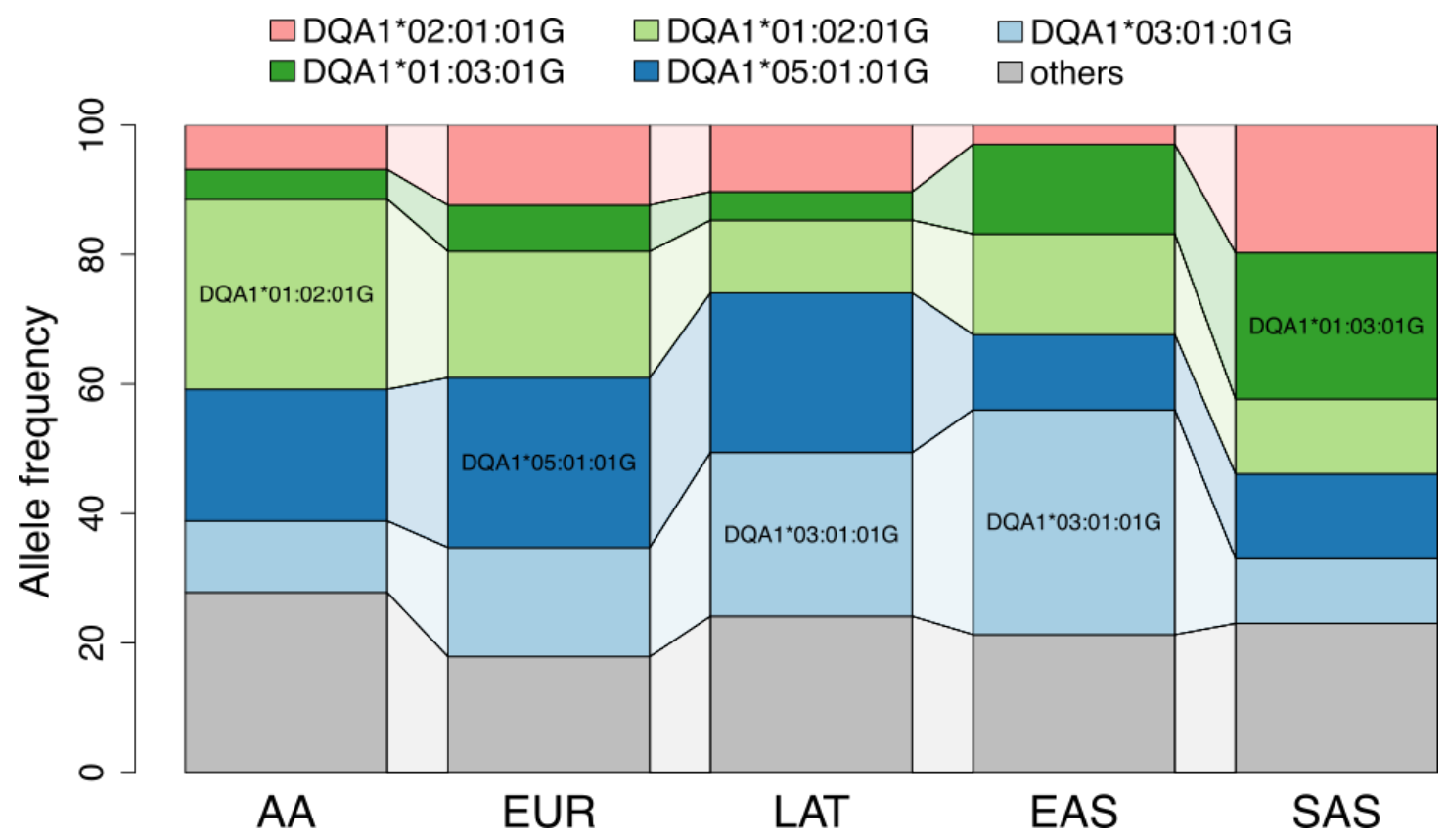


meqRxiv preprint doi: https://doi.org/10.1101/2020.07.16.20155606; this version posted July 18, 2020. The copyright holder for this preprint

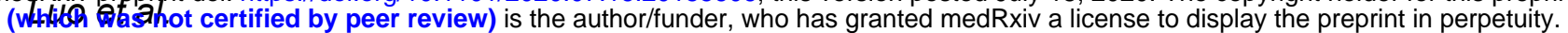

It is made available under a CC-BY-NC 4.0 International license .

\section{Figure 2. Pairwise LD and haplotype structure for six classical HLA genes in five}

758 population groups. (a) shows the pairwise normalized entropy $(\varepsilon)$ measuring the difference of

759 the haplotype frequency distribution for linkage disequilibrium and linkage equilibrium among

760 five population groups. It takes values between 0 (no LD) to 1 (perfect LD). (b) shows the

761 haplotype structures of the eight classical HLA genes in each population. The tile in a bar

762 represents an $H L A$ allele, and its height corresponds to the frequencies of the $H L A$ allele. The

763 gray lines connecting between two alleles represent $H L A$ haplotypes. The width of these lines

764 corresponds to the frequencies of the haplotypes. The most frequent long-range HLA

765 haplotypes within each population is bolded and highlighted in a color described by the key at

766 the bottom.

767 (a)

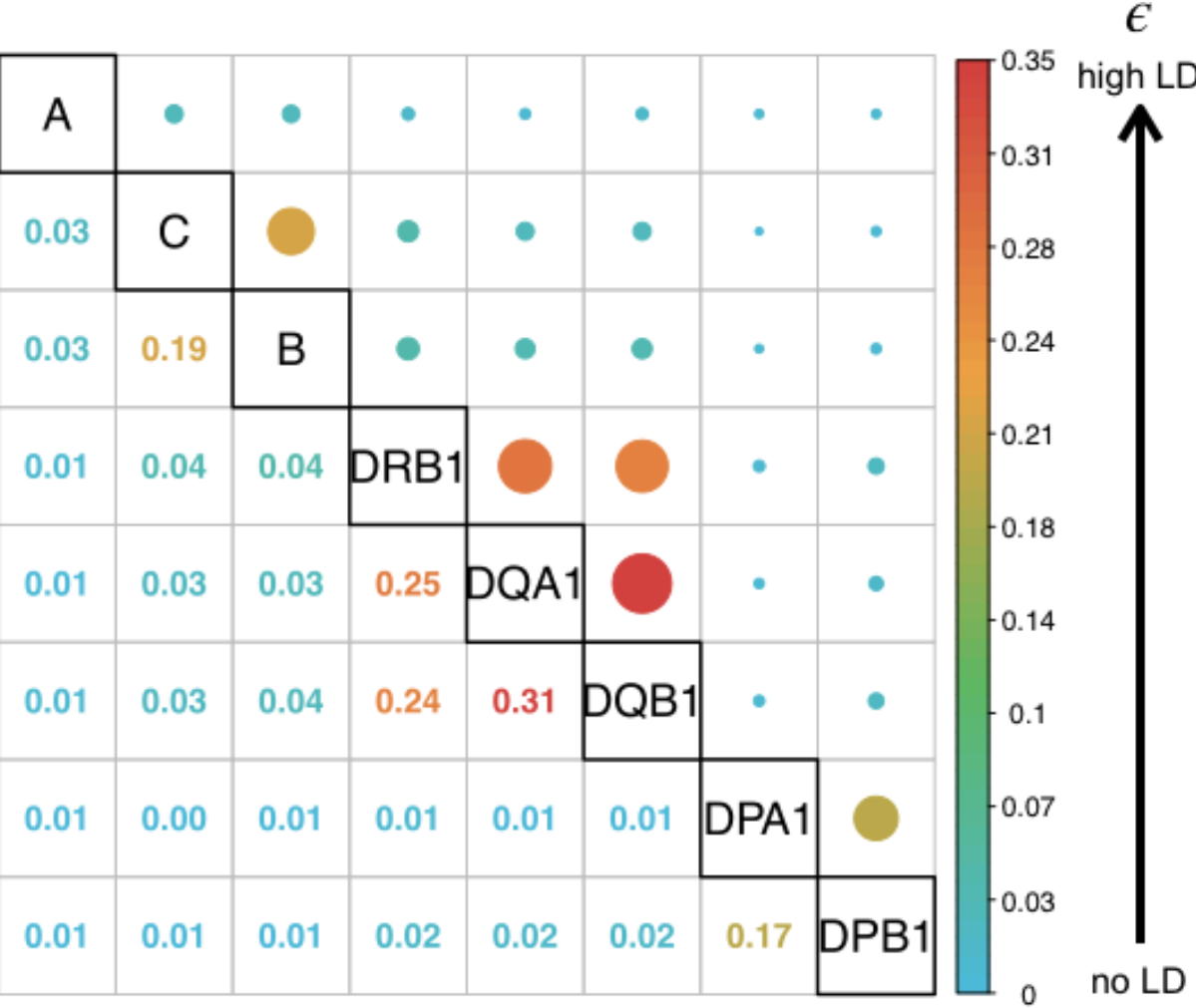


meqRxiv preprint doi: https://doi.org/10.1101/2020.07.16.20155606; this version posted July 18, 2020. The copyright holder for this preprint

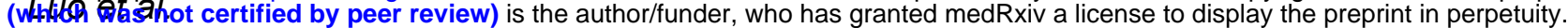

It is made available under a CC-BY-NC 4.0 International license .

768 (b)

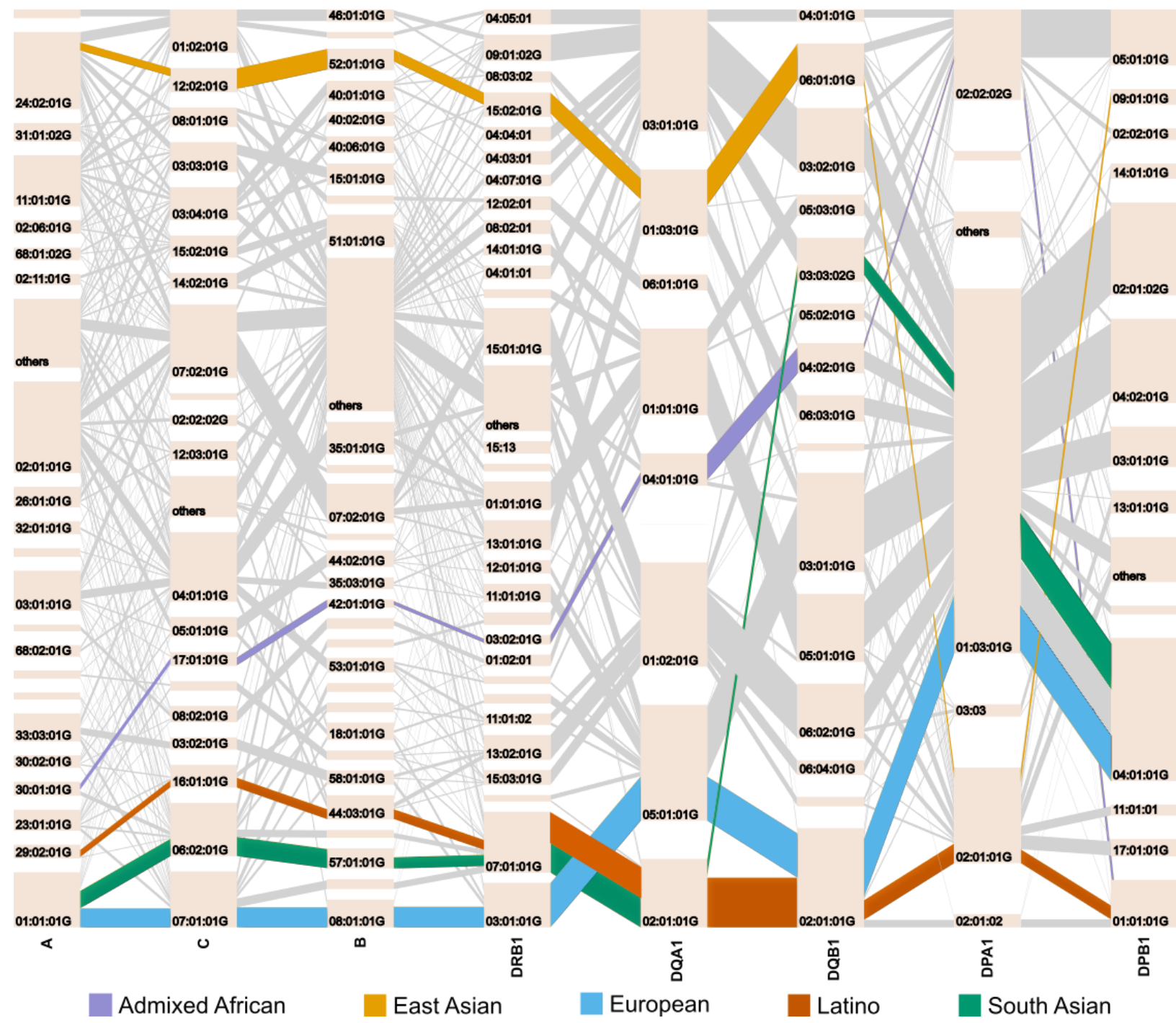


meqRxiv preprint doi: https://doi.org/10.1101/2020.07.16.20155606; this version posted July 18, 2020. The copyright holder for this preprint

( $W_{1}+69$ Q

It is made available under a CC-BY-NC 4.0 International license .

769 Figure 3. The multi-ethnic HLA reference panel shows improvement in allele diversity and

770 imputation accuracy. (a). The number of HLA alleles at the two-field resolution included in the

771 multi-ethnic HLA reference panel $(\mathrm{N}=21,546)$ compared to the European only Type 1 Diabetes

772 Genetics Consortium ${ }^{48}$ (T1DGC) panel $(N=5,225)$ as well as a subset of the multi-ethnic HLA

773 panel down-sampled to the same size as T1DGC. (b). The correlation between imputed and

774 typed dosages of classical HLA alleles using the multi-ethnic HLA reference panel at one-filed

775 (red), two-field (blue) and G-group resolution (black) of the 9551000 Genomes subjects. (c).

776 The imputation accuracy for five classical HLA genes at one-field, two-field and G-group

777 resolution. (d). The imputation accuracy at G-group resolution of the 1000 Genomes subjects

778 stratified by four diverse ancestries when using three different imputation reference panels as

779 described in (a). 
meqRxiv preprint doi: https://doi.org/10.1101/2020.07.16.20155606; this version posted July 18, 2020. The copyright holder for this preprint (whith 9 thashot certified by peer review) is the author/funder, who has granted medRxiv a license to display the preprint in perpetuity.

It is made available under a CC-BY-NC 4.0 International license .

(a) Reference panels $\square$ Multi-ethnic WGS $(21,546) \square$ Down-sampled WGS $(5,225) \square$ T1DGC $(5,225)$

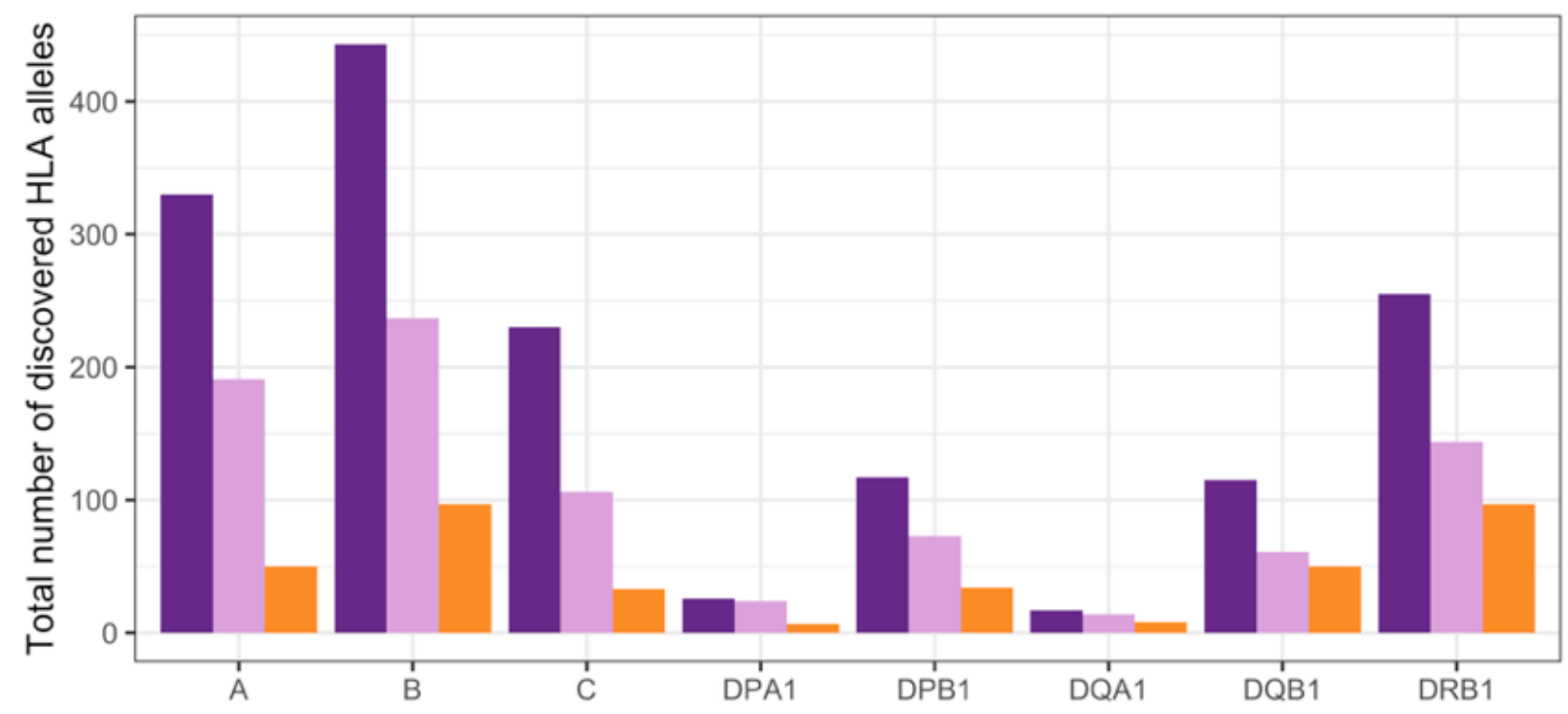

(b)

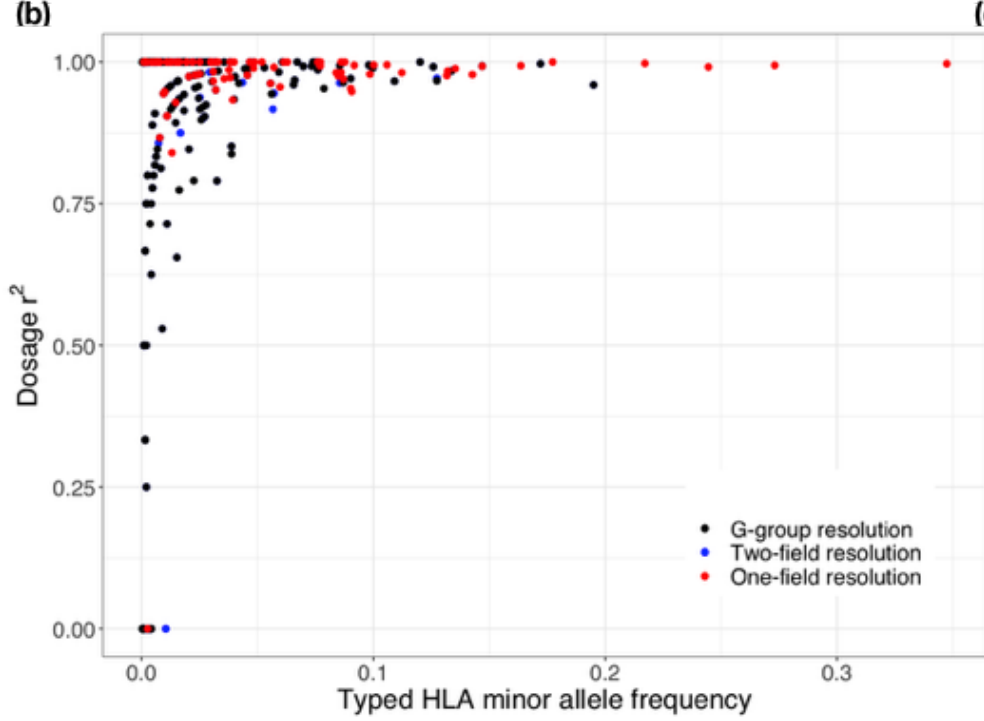

(c)

\begin{tabular}{|c|c|c|c|}
\hline & $\begin{array}{c}\text { one- } \\
\text { field }\end{array}$ & $\begin{array}{c}\text { two- } \\
\text { field }\end{array}$ & G-group \\
\hline$A$ & 0.992 & 0.964 & 0.963 \\
\hline$B$ & 0.972 & 0.937 & 0.930 \\
\hline$C$ & 0.995 & 0.969 & 0.981 \\
\hline$D Q B 1$ & 0.993 & 0.981 & 0.933 \\
\hline$D R B 1$ & 0.976 & 0.938 & 0.934 \\
\hline
\end{tabular}


meqRxiv preprint doi: https://doi.org/10.1101/2020.07.16.20155606; this version posted July 18, 2020. The copyright holder for this preprint

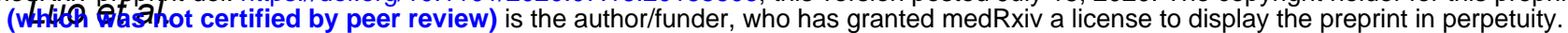

It is made available under a CC-BY-NC 4.0 International license .

(d)
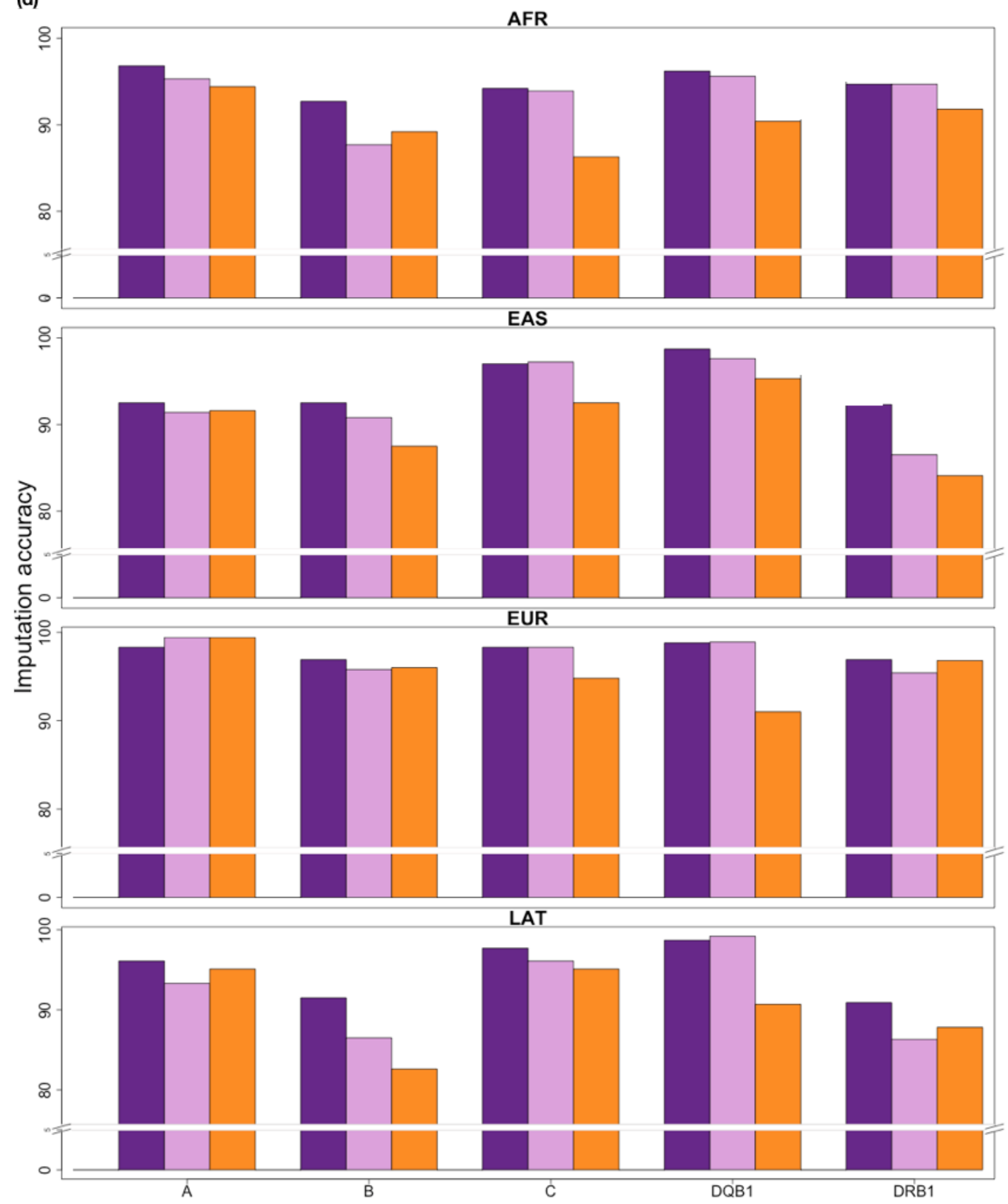
meqRxiv preprint doi: https://doi.org/10.1101/2020.07.16.20155606; this version posted July 18, 2020. The copyright holder for this preprint

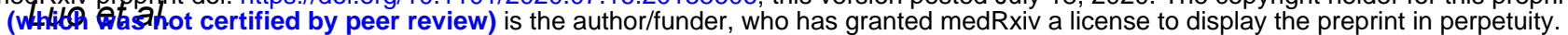
It is made available under a CC-BY-NC 4.0 International license.

780 Figure 4. Stepwise conditional analysis of the allele and amino acid positions of classical

781 HLA genes to HIV-1 viral load. Each circle point represents the linear regression -log10(

$\left.782 P_{\text {binary }}\right)$ for all classical $H L A$ alleles. Each diamond point represents $-\log 10\left(P_{\text {omnibus }}\right)$ for the

783 tested amino acid positions in HLA (blue=HLA- $A$; yellow=HLA-C; red=HLA- $B$;

784 lightblue=HLA-DRB1; green=HLA-DQA1; purple=HLA-DQB1, darkgreen=HLA-DPA1;

785 lightgreen=HLA-DPB1). Association at amino acid positions with more than two alleles was

786 calculated using a multi-degree-of-freedom omnibus test. The dashed blacked line represents

787 the significance threshold of $P=5 \times 10^{-8}$. Each panel shows the association plot in the process

788 of stepwise conditional omnibus test. (a) One-field classical allele $B^{\star} 57\left(P=9.84 \times 10^{-138}\right)$ and

789 (b) amino acid position 97 in HLA-B $\left(P_{\text {omnibus }}=2.86 \times 10^{-184}\right)$ showed the strongest association

790 signal. Results conditioned on position 97 in HLA-B showed a secondary signal at (c) classical

791 allele $B^{*} 81: 0101: G\left(P=4.53 \times 10^{-23}\right)$ and $(\mathbf{d})$ position 67 in HLA-B $\left(P_{\text {omnibus }}=1.08 \times 10^{-40}\right)$.

792 Results conditioned on position 97 and 67 in HLA-B showed the same classical allele (e)

$793 B^{\star} 81: 0101 G\left(P=2.70 \times 10^{-23}\right)$ and $(\mathbf{f})$ third signal at position 156 in HLA-B (

$\left.794 P_{\text {omnibus }}=1.92 \times 10^{-30}\right)$. Results conditioned on position 97, 67 and 156 int HLA-B showed a

795 fourth signal at $(\mathbf{g}) \mathrm{HLA}-A^{*} 31\left(P=2.45 \times 10^{-8}\right)$ and $(\mathbf{h})$ position 77 in HLA-A (

$796 P_{\text {omnibus }}=5.35 \times 10^{-7}$ ) outside HLA-B. 
meqRxiv preprint doi: https://doi.org/10.1101/2020.07.16.20155606; this version posted July 18, 2020. The copyright holder for this preprint ( $w$ Hith 解定hot certified by peer review) is the author/funder, who has granted medRxiv a license to display the preprint in perpetuity. It is made available under a CC-BY-NC 4.0 International license .

(a)
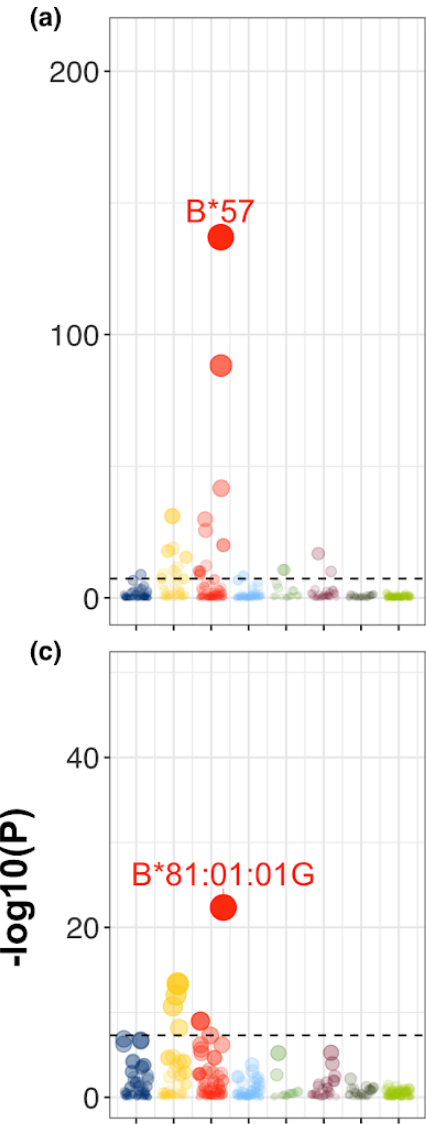

(e)

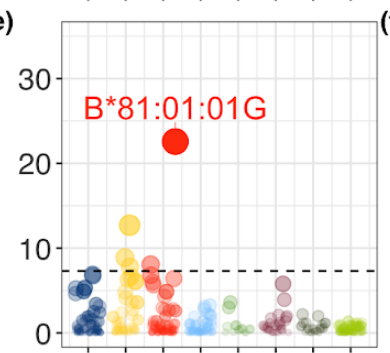

(g)

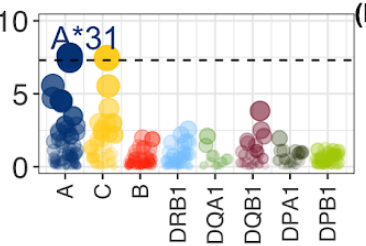

Classical allele positions (b)

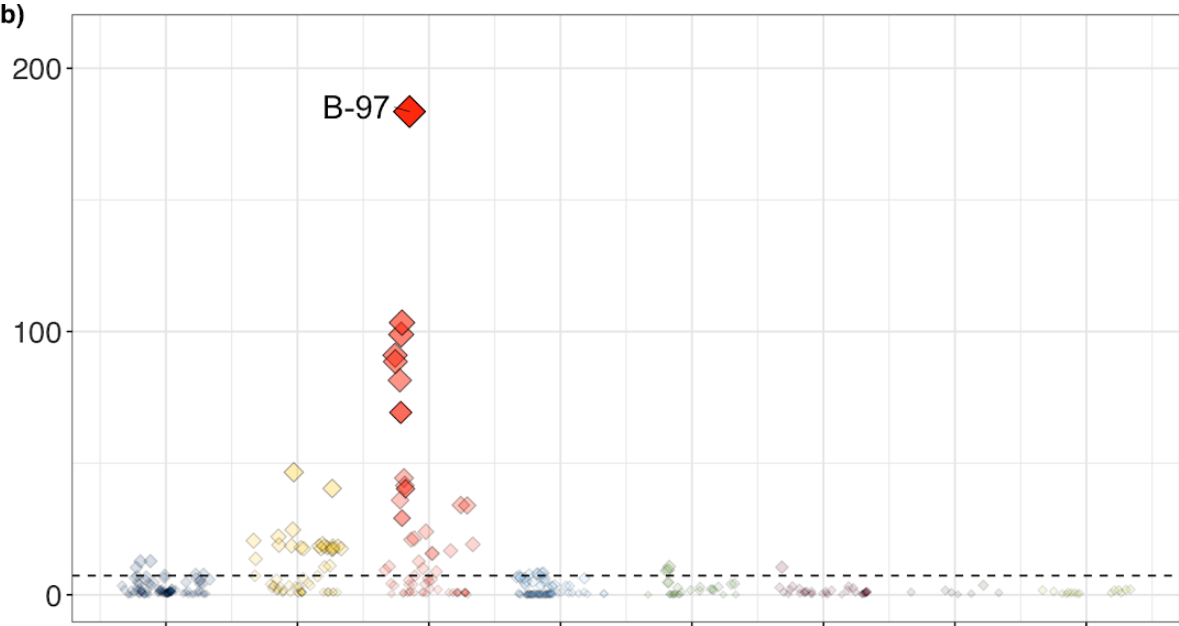

(d)

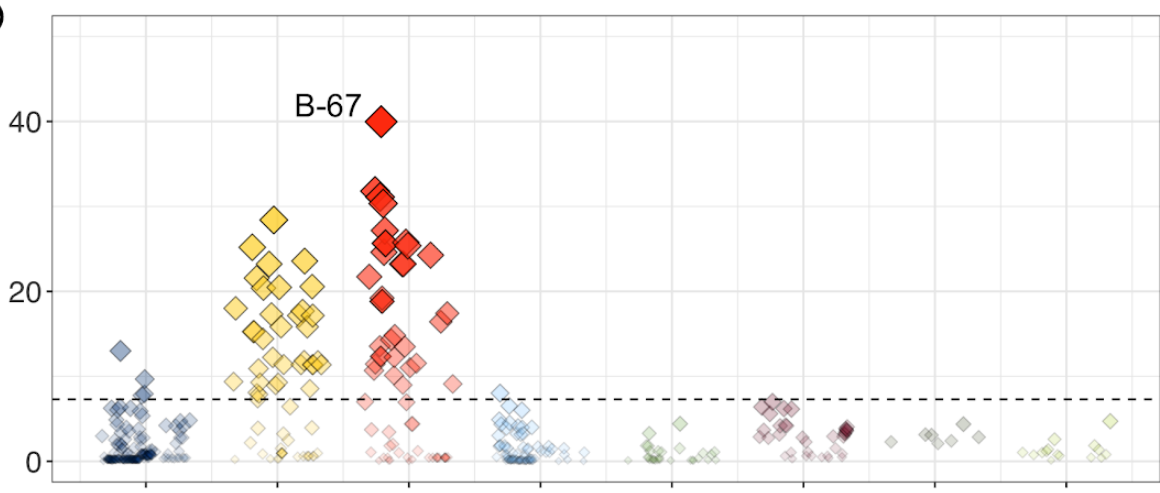

(f)
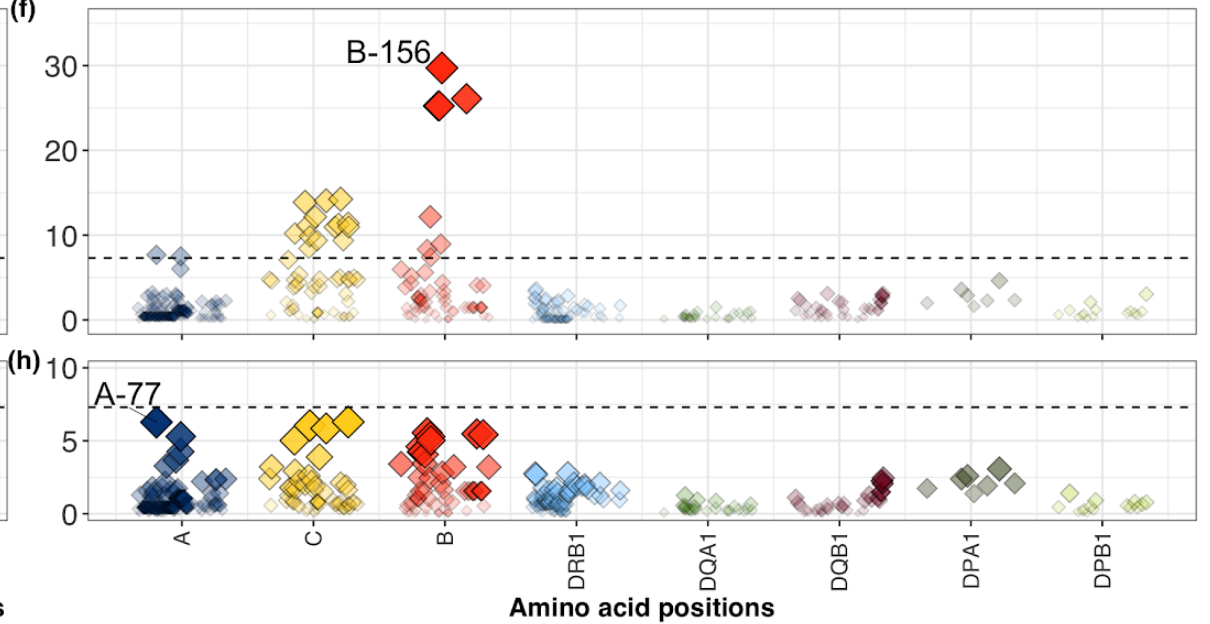
meqRxiv preprint doi: https://doi.org/10.1101/2020.07.16.20155606; this version posted July 18, 2020. The copyright holder for this preprint

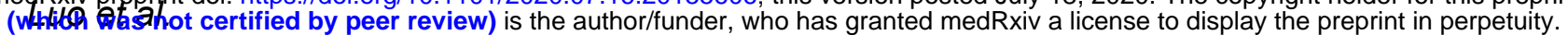

It is made available under a CC-BY-NC 4.0 International license .

797 Figure 5. Location and effect of three independently associated amino acid positions in

798 HLA-B. (a) Allele frequency of six residues at position 97 in HLA-B among three populations.

799 (b) Effect on spVL (i.e., change in log10 HIV-1 spVL per allele copy) of individual amino acid

800 residues at position 97 in HLA-B. Results were calculated per allele using linear regression

801 models, including gender and principal components within each ancestry as covariates. (c)

802 HLA-B (PDB ID code 2bvp) proteins. Omnibus and stepwise conditional analysis identified three

803 independent amino acid positions (positions 97 (red), 67 (orange), and 156 (green) in HLA-B.

804 (d) Effect on spVL (i.e., change in log10 HIV-1 spVL per allele copy) of individual amino acid

805 residues at each position reported in this and previous work ${ }^{10,16}$. Results were calculated per

806 allele using linear regression models. The x-axis shows the effect size and its standard errors in

807 the joint analysis, and the y-axis shows the effect size and its standard error in individual

808 populations $($ purple $=$ Admixed American; blue $=$ European and orange $=$ Latino $) .(\mathbf{e})$ Variance of

809 spVL explained by the haplotypes formed by different amino acid positions. 
meqRxiv preprint doi: https://doi.org/10.1101/2020.07.16.20155606; this version posted July 18, 2020. The copyright holder for this preprint

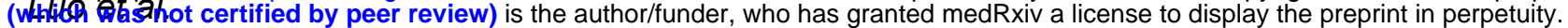

It is made available under a CC-BY-NC 4.0 International license .
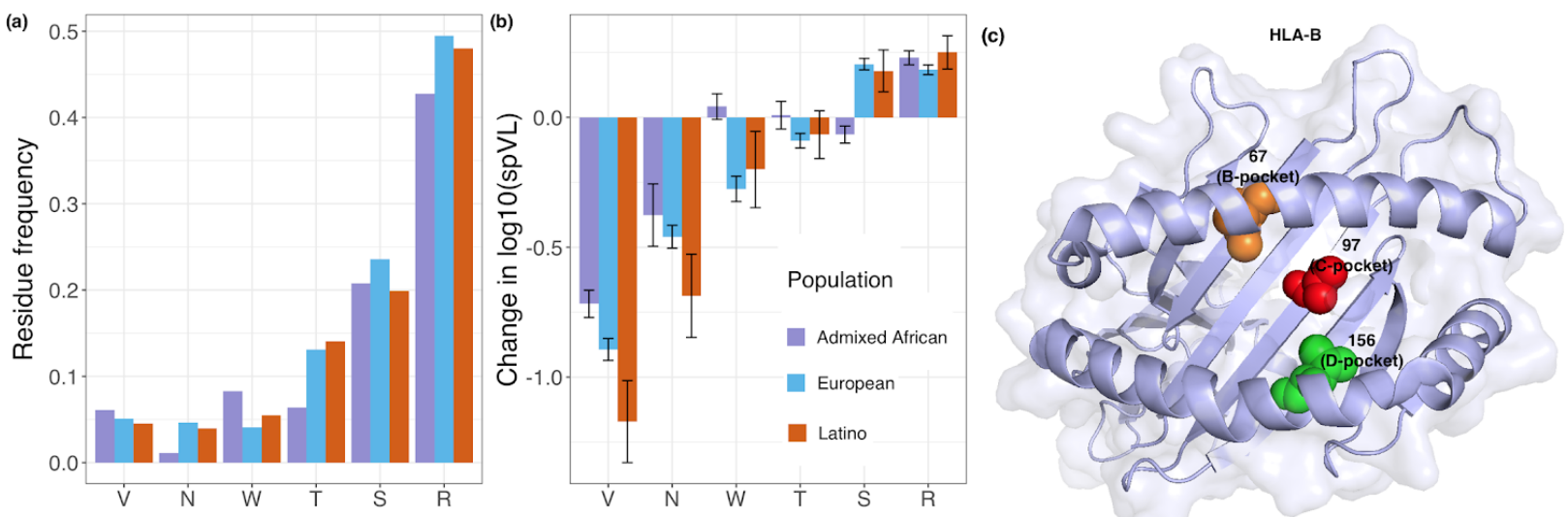

Amino acid residues at position 97 in HLA-B

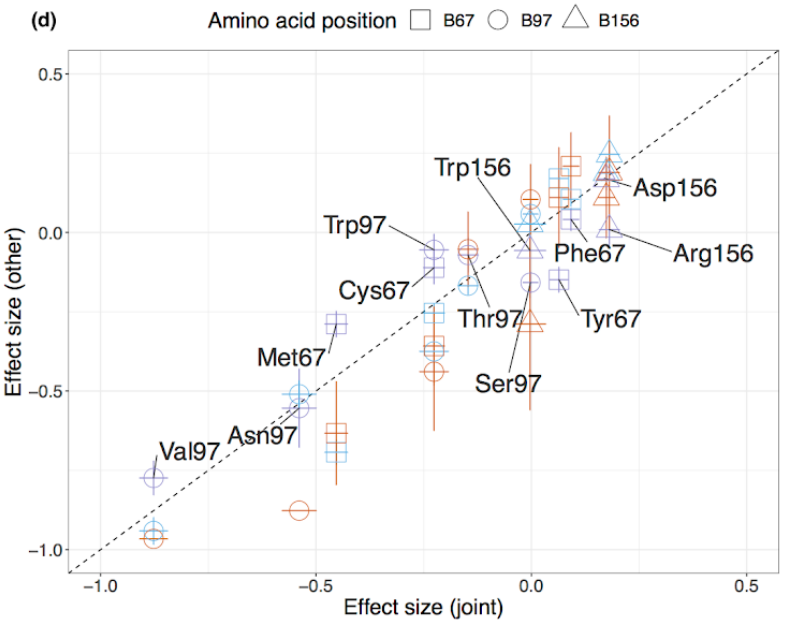

(e)

B97 B97+B67 $\mathrm{B} 97+\mathrm{B} 67+\mathrm{B} 156$

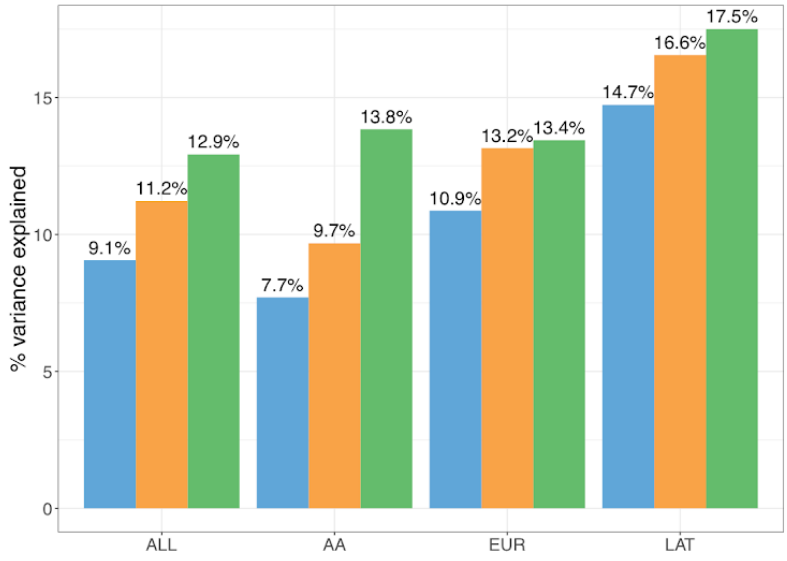


meqRxiv preprint doi: https://doi.org/10.1101/2020.07.16.20155606; this version posted July 18, 2020. The copyright holder for this preprint (WHikh Q It is made available under a CC-BY-NC 4.0 International license .

\section{Tables}

811 Table 1. Effect estimates for the haplotypes defined by the three independent amino

812 acids in HLA-B associated with HIV-1 viral load. Only haplotypes with $>1 \%$ frequency in the

813 overall population are listed (Supplementary Table 15). Classical alleles of HLA-B are grouped

814 based on the amino acid residues presented at position 97, 67 and 156 in HLA-B. For each

815 haplotype, the multivariate effect is given as an effect size, taking the most frequent haplotype

$816(97 \mathrm{R}-67 \mathrm{~S}-156 \mathrm{~L})$ as the reference (effect size $=0)$. Heterogeneity $\mathrm{p}$-value $(\mathrm{P}(\mathrm{het}))$ of each

817 haplotype is calculated using a F-statistics with two degrees of freedom (Methods). Effect size

818 and its standard error in each population are listed only for haplotypes that show evidence of

819 heterogeneity $(P$-value $<0.05 / 26$, bolded). Unadjusted haplotype frequencies are given in each

820 population.

\begin{tabular}{|c|c|c|c|c|c|c|c|c|c|c|c|c|}
\hline \multicolumn{3}{|c|}{ HLA-B amino acid at position } & \multicolumn{4}{|c|}{ Effect size (standard error) } & \multirow[b]{2}{*}{$P($ het) } & \multicolumn{4}{|c|}{ Unadjusted allele frequency } & \multirow[t]{2}{*}{$\begin{array}{l}\text { HLA-B } \\
\text { allele }\end{array}$} \\
\hline 97 & 67 & 156 & AA & EUR & LAT & Joint & & AA & EUR & LAT & Joint & \\
\hline V & M & L & & & & $\begin{array}{l}-0.921 \\
(0.036)\end{array}$ & 0.031 & 0.056 & 0.049 & 0.059 & 0.051 & $\begin{array}{c}B^{*} 57: 01 ; B^{*} \\
57: 03\end{array}$ \\
\hline $\mathrm{N}$ & C & L & & & & $\begin{array}{l}-0.554 \\
(0.041)\end{array}$ & 0.257 & 0.012 & 0.046 & 0.037 & 0.035 & $B^{*} 27: 05$ \\
\hline T & s & L & & & & $\begin{array}{l}-0.436 \\
(0.041)\end{array}$ & 0.041 & 0.028 & 0.039 & 0.056 & 0.037 & $\begin{array}{c}B^{*} 13: 02 ; B^{\star} \\
52: 01\end{array}$ \\
\hline w & c & L & & & & $\begin{array}{l}-0.397 \\
(0.041)\end{array}$ & 0.581 & 0.03 & 0.039 & 0.054 & 0.037 & $\begin{array}{c}B^{*} 14: 01 ; B^{*} \\
14: 02\end{array}$ \\
\hline $\mathrm{s}$ & $\mathrm{s}$ & L & & & & $\begin{array}{l}-0.252 \\
(0.066)\end{array}$ & 0.013 & 0.002 & 0.014 & 0.07 & 0.013 & $B^{*} 40: 02$ \\
\hline $\mathrm{R}$ & $\mathrm{s}$ & W & & & & $\begin{array}{l}-0.177 \\
(0.038)\end{array}$ & 0.618 & 0.009 & 0.062 & 0.028 & 0.044 & $\begin{array}{c}15: 10 ; B^{\star} 15: \\
16\end{array}$ \\
\hline T & $\mathrm{F}$ & L & & & & $\begin{array}{l}-0.125 \\
(0.036)\end{array}$ & 0.001 & 0.03 & 0.059 & 0.073 & 0.051 & $\begin{array}{c}B^{*} 51: 01 ; B^{*} \\
78: 01\end{array}$ \\
\hline $\mathrm{R}$ & M & L & & & & $\begin{array}{l}-0.125 \\
(0.045)\end{array}$ & 0.375 & 0.061 & 0.014 & 0.028 & 0.029 & $\begin{array}{c}B^{\star} 15: 16 ; B^{\star} \\
58: 01\end{array}$ \\
\hline $\mathrm{R}$ & C & L & & & & $\begin{array}{l}-0.078 \\
(0.039)\end{array}$ & 0.055 & 0.042 & 0.039 & 0.06 & 0.041 & $\begin{array}{c}15: 16 ; B^{\star} 39: \\
10\end{array}$ \\
\hline $\mathrm{R}$ & $\mathrm{s}$ & D & $\begin{array}{c}0.165 \\
(0.056)\end{array}$ & $\begin{array}{c}-0.07 \\
(0.034)\end{array}$ & $\begin{array}{l}-0.153 \\
(0.173)\end{array}$ & $\begin{array}{l}-0.019 \\
(0.028)\end{array}$ & 0.002 & 0.075 & 0.108 & 0.084 & 0.097 & $\begin{array}{c}44: 02 ; B^{*} 45: \\
01\end{array}$ \\
\hline $\mathrm{R}$ & $\mathrm{s}$ & L & & & & Reference & 0.536 & 0.191 & 0.176 & 0.197 & 0.18 & $\begin{array}{l}\text { 15:10; } B^{\star} 18: \\
01 ; B^{*} 39: 10\end{array}$ \\
\hline $\mathrm{s}$ & $\mathrm{Y}$ & D & & & & $\begin{array}{c}0.015 \\
(0.055)\end{array}$ & 0.884 & 0.059 & NA & 0.017 & 0.019 & $\begin{array}{c}B^{*} 42: 01 ; B^{*} \\
42: 02\end{array}$ \\
\hline $\mathrm{s}$ & $\mathrm{Y}$ & $\mathrm{R}$ & $\begin{array}{l}-0.06 \\
(0.055)\end{array}$ & $\begin{array}{c}0.037 \\
(0.033)\end{array}$ & $\begin{array}{l}-0.002 \\
(0.187)\end{array}$ & $\begin{array}{c}0.022 \\
(0.027)\end{array}$ & 0.007 & 0.08 & 0.124 & 0.07 & 0.108 & $\begin{array}{c}B^{*} 07: 02 ; B^{\star} \\
07: 05\end{array}$ \\
\hline$s$ & $\mathrm{~F}$ & D & & & & $\begin{array}{c}0.041 \\
(0.031)\end{array}$ & 0.218 & 0.034 & 0.095 & 0.042 & 0.074 & $B^{*} 08: 01$ \\
\hline $\mathrm{R}$ & $\mathrm{F}$ & L & & & & $\begin{array}{c}0.045 \\
(0.027)\end{array}$ & 0.73 & 0.182 & 0.095 & 0.113 & 0.122 & $\begin{array}{c}B^{*} 35: 01 ; B^{*} \\
53: 01\end{array}$ \\
\hline W & M & L & & & & $\begin{array}{c}0.098 \\
(0.064)\end{array}$ & 0.268 & 0.046 & NA & NA & 0.014 & $B^{*} 58: 02$ \\
\hline T & $\mathrm{Y}$ & L & & & & $\begin{array}{c}0.176 \\
(0.058)\end{array}$ & 0.207 & 0.005 & 0.021 & NA & 0.016 & \\
\hline
\end{tabular}

